This is the post-print version of this article: Roach, M. and Meeus, L., 2020. The welfare and price effects of sector coupling with power-to-gas. Energy economics, 86, p.104708.

DOI: $10.1016 /$ i.eneco.2020.104708

\title{
The Welfare and Price Effects of Sector Coupling with Power-to-Gas
}

\author{
Martin Roach ${ }^{\mathrm{a}, \mathrm{c}}$, Leonardo Meeus ${ }^{\mathrm{a}, \mathrm{b}}$ \\ aVlerick Energy Centre, Vlerick Business School, Avenue du Boulevard 21, 1210 Bruxelles, \\ Belgium
}

${ }^{b}$ Florence School of Regulation, Robert Schumann Centre for Advanced Studies, European University Institute, Via Giovanni Boccaccio, 121, 50133 Firenze FI, Italy

${ }^{c} \mathrm{KU}$ Leuven, Faculty of Economics and Business, Naamsestraat 69, 3000 Leuven, Belgium

Corresponding Author: Martin Roach, martin.roach@vlerick.com

\begin{abstract}
Electricity markets with high installed capacities of Variable Renewable Energy Sources (VRES) experience periods of supply and demand mismatch, resulting in near-zero and even negative prices, or energy spilling due to surplus. The participation of emerging Power-to-X solutions in a sector coupling paradigm, such as Power-to-Gas (PTG), has been envisioned to provide a source of demand flexibility to the power sector and decarbonize the gas sector. We advance a long-run equilibrium model to study the PTG investment decision from the point of view of a perfectly competitive electricity and gas system where each sector's market is cleared separately but coupled by PTG. Under scenarios combining PTG technology costs and electricity RES targets, we study whether or not there is a convergence in the optimal deployment of PTG capacity and what is the welfare distribution across both sectors. We observe that PTG can play an important price-setting role in the electricity market, but PTG revenues from arbitrage opportunities erodes as more PTG capacity is installed. We find that the electricity and gas sector have aligned incentives to cooperate around PTG, and instead find an issue of misaligned incentives related to the PTG actor. Although not the focus of our analysis, in some scenarios we find that the welfare optimal PTG capacity results in a loss for the PTG actor, which reveals some intuition that subsidizing PTG can make sense to reduce the cost of RES subsidies. Sensitivity analyses are conducted to contextualize these findings for system specificities.
\end{abstract}

\section{Keywords}

Sector coupling; power-to-gas; renewable energy sources; mixed complementarity problem 


\section{Introduction}

Electricity markets with high installed capacities of Variable Renewable Energy Sources (VRES) experience periods of supply and demand mismatch, resulting in near-zero and even negative prices, or energy spilling due to surplus. Ambitious Renewable Energy Sources (RES) targets and Greenhouse Gas (GHG) emissions reduction objectives in the EU could aggravate this problem further. In deploying more VRES in order to meet these RES targets, more regions will have production surplus above peak demand. According to Jones et al. (2018), this 'RES Peak' issue will become a regular and important seasonal feature of EU electricity markets. The authors highlight the National Energy and Climate plans, which to be on trajectory, the share of renewable electricity as a percentage of electricity by 2030 for Member States is expected to be: Belgium (40.4\%); Denmark (greater than 100\%); France (40\%); Germany (65\%); Italy (55.4\%); Netherlands (66\%); Portugal (80\%); and Spain (74\%) (Jones et al., 2018). A portfolio of technologies can address the 'RES Peak' issue, and Powerto-Gas (PTG), producing hydrogen through electrolysis, is one of them. PTG has the potential to provide a source of demand flexibility to the power sector and decarbonize the gas sector. Other possible solutions to deal with the 'RES Peak' issue include demand response, battery storage, pumped hydro storage and curtailment. Blanco and Faaij (2018) published a review of studies that characterizes PTG relative to other technologies able to deliver flexibility to the power sector. The emergence of other Power-to-X solutions, such as Power-to-Heat or Powerto-Liquids, could also decarbonize other sectors.

In the academic literature, the role of PTG has been studied in a variety of contexts demonstrating its complementarity and competitiveness. The role of PTG in a sector coupling - electricity, gas and CO2 - framework is modeled by Vandewalle et al. (2015). They observe PTG setting the electricity market price in a 100\% VRES electricity system and flexibility requirements in the gas system increasing due to PTG's participation.

Belderbos et al. (2017) take a methodological approach to determining storage needs in order to calculate an optimal storage portfolio. The authors distinguish storage technologies such as power-to-gas from batteries based on installed charging power, discharging power and energy storage. Li et al. (2019) investigate a case study on linking electricity and gas networks to produce hydrogen via PTG in a city in Japan was investigated using a simulation model. The authors find that the required optimal electrolyzer size increases with increasing the PV fraction ratio of combined renewable production. Tlili et al. (2019) conduct a case study on the production of hydrogen via PTG for France. The authors find that the potential of hydrogen production in France using electricity surplus is overestimated unless you take into account interconnections which can impact flexibility needs of the electric system. PTG is studied from the point of view of portfolio effects of holding different generation and PTG technologies using a stochastic Mixed Complementarity Problem (MCP) in Lynch et al. (2018). They find that the participation of PTG has the potential to make other technologies more or less profitable. It is true that PTG competes against other technologies, however this is not the focus of this paper, where we only consider PTG to deal with the 'RES Peak' issue.

With few exceptions, the previously cited academic studies overlook the potential misalignment in incentives to install PTG. For instance, Green et al. (2011) demonstrate how the short run opportunity to produce hydrogen is eroded when the generation capacity mix changes in response to wind and hydrogen electrolyzer capacities being installed. Assuming PTG is competitive, a new concern is if the support for PTG from the electricity and gas sector diverges due to the impact PTG's presence may have on the redistribution of welfare across sectors or market players, then investments in PTG may never materialize. The aim of this paper is to study the PTG investment decision from the point of view of a perfectly competitive 
electricity and gas system where each sector's market is cleared separately but coupled by PTG. We study whether or not there is a convergence in the optimal deployment of PTG capacity and what the welfare distribution is across both sectors. This research question may contribute to the ongoing policy debate in the EU concerning the contestability of PTG. ACER and CEER (2019) discuss the regulatory framework for treating PTG as a regulated or competitive asset.

MCPs have been advanced for a large range of problems found in the energy sector and have certain advantages inherent in combining the optimization problems of multiple agents and in constraining primal and dual variables together, which has motivated this chosen method (Gabriel et al., 2013). Saguan and Meeus (2014) study a similar problem in alignment in incentives for transmission investment in interconnectors between countries to costeffectively integrate RES using a MCP formulation, but the authors only considered an electricity system. del Valle et al. (2017) use an MCP formulation to model wholesale gas markets while incorporating gas demand from the electric power sector, but the direct participation of sector coupling assets such as PTG is absent. Inspired by the previous sectorspecific MCP models, we propose a stylized long term equilibrium model which is built up using a MCP formulation. We study the welfare distribution and price effects at sector optimal capacities of PTG to know if we can expect a misalignment in incentives between the electricity and gas sector at the long-run equilibrium. The MCP model we advance contributes to the literature demonstrating an approach using this methodology to study sector coupling topics.

This paper is organized in two main sections. Section 2 describes how we build up the model and the underlying assumptions. Section 3 details the results from a numerical example. Lastly, our key findings are summarized in the conclusion.

\section{Methodology}

First of all, our modelling approach is described in Section 2.1. Second of all, the mathematical formulation is provided in Section 2.2.

\subsection{Modelling Approach}

Our stylized model simulates the long-run equilibrium of an integrated wholesale electricity and gas market which have sector specific market clearing constraints coupled through the participation of PTG. The electricity and gas market are perfectly competitive. One renewable and two conventional gas generators participate in the electricity market investing in capacity and bidding their variable costs. The variable costs of the conventional gas generators depends on the gas market price while the renewable generator has no variable costs. Electricity consumers and gas consumers are represented by an aggregate inelastic demand. PTG is represented as an additional source of demand which consumes electricity, converts it into hydrogen and subsequently blends it into the gas network. PTG is a source of supply to the gas market as such and is modelled as perfectly substitutable. The rest of the gas supplied on the gas market originates from shippers who procure gas via long term contracts under a specified cost structure. A market clearing constraint which balances supply and demand in the electricity and gas market, respectively, determines each market's price. However, PTG and the conventional gas generators are linking technologies participating in both markets and therefore affect prices through arbitrage opportunities. The model is depicted schematically in Figure 1 and relates each agent's optimization problems described further in the mathematical formulation.

PTG capacity is exogenously defined. Multiple iterations are executed in the model, for each iteration, investment in PTG capacity increases by $50 \mathrm{MW}$ increments, reflecting the lumpiness of such investments, and the market clearing conditions lead to an equilibrium in 
the electricity and gas market simultaneously. In each iteration, the operation of the PTG assets responds to prices in both markets under a short-run profit constraint and is constrained by its exogenous installed capacity. For each model run, we analyze the evolution of sector welfare, PTG profits and total welfare as PTG capacity is increased in order to identify sectorspecific equilibrium and system optimal points. This solution method is used in the primary version of the model. Slight variations of the model are advanced to simulate the endogenization of the PTG capacity investment decision, hydrogen injection limits and a carbon price on conventional gas generators. The use of these model variations are further described in the mathematical formulation and clearly linked to specific result sections.

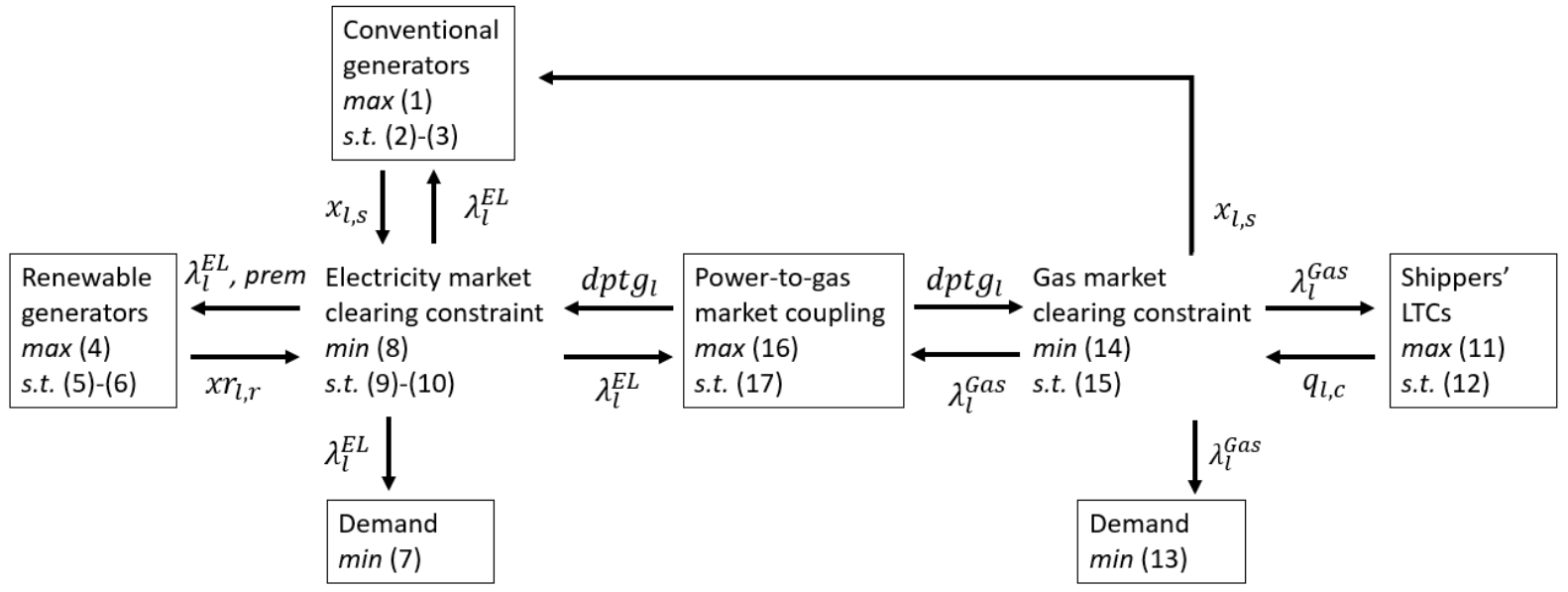

Figure 1: Schematic overview of market coupling with PTG, including references to the optimization problems (1)(17) of the agents (cf. Section 2.2)

The model is designed for an energy system that has I periods, where each period is $\mathrm{T}_{1}$ hours and $\sum_{l \in L}\left(\mathrm{~T}_{1}\right)=8760$ hours. The formulation uses representative hours, so the market clearing prices and quantities solved at a per period resolution are extended to all hours in $\mathrm{T}_{1}$.

\subsection{Mathematical formulation}

In this section, the problems of all agents are presented. The dual variables associated with each constraint are given in between parentheses.

\subsubsection{Electricity Market}

\section{Conventional generators}

The decision variables of each conventional generation technology s are its installed capacity $g_{s}$ and its hourly generation $x_{l, s}$. The optimization problem of each conventional generator is defined as (1)-(3):

$$
\text { Maximize } \sum_{l \in L}\left(\left(\lambda_{l}^{E L}-\mathrm{VC}_{\mathrm{s}}-\lambda_{l}^{G a s}\right) \cdot x_{l, s} \bullet \mathrm{T}_{\mathrm{l}}\right)-\mathrm{CC}_{\mathrm{s}} \bullet \mathrm{g}_{\mathrm{s}}
$$

Subject to

$$
\begin{aligned}
& 0 \leq x_{l, s} \leq g_{s}, \forall l \in L, \forall s \in S \quad\left(\rho_{l, s}^{-}, \rho_{l, s}^{+}\right) \\
& 0 \leq g_{s}, \quad \forall s \in S\left(\xi_{s}\right)
\end{aligned}
$$

Each generator maximizes its profit, subtracting its operational and investment costs from its market revenues. For each generation technology type $\mathrm{s}$, variables costs are defined as $\mathrm{VC}_{\mathrm{s}}$ and annualized investment costs as $\mathrm{CC}_{s} . \mathrm{VC}_{\mathrm{s}}$ can also carry a carbon price once scaled in terms of MWh. Since the conventional generators later introduced are Gas Fired Power Plants (GFPP), the price of gas $\lambda_{l}^{G a s}$ is also included as a variable cost component in the optimization 
problem. Through constraint (2), production in a given period is constrained by the installed generation capacity in all periods. We assume that conventional generation is $100 \%$ available over the year. When a generation technology type $s$ is producing at its maximum, $\rho_{l, s}^{+} \geq 0$, a generator's bid into the electricity market in peak hours is derived from this dual variable. In this way, the generator acquires scarcity rents which contribute to recovering its investment costs.

\section{Renewable generators}

The decision variables of each renewable generation technology $r$ are its installed capacity $g r_{r}$ and its hourly generation $x r_{l, r}$. The optimization problem of each renewable generator is defined as (4)-(6):

$$
\begin{aligned}
& \quad \text { Maximize } \sum_{l \in L}\left(\left(\lambda_{l}^{E L}-\mathrm{VCR}_{\mathrm{r}}\right) \cdot x r_{l, r} \bullet \mathrm{T}_{\mathrm{l}}\right)-\mathrm{CC}_{\mathrm{r}} \bullet g r_{r}+\sum_{l \in L}\left(g r_{r} \bullet \text { prem } \bullet \mathrm{T}_{\mathrm{l}}\right) \\
& \text { Subject to } \\
& 0 \leq x r_{l, r} \leq g r_{r} \bullet \mathrm{AVA}_{\mathrm{l}, \mathrm{r}}, \forall l \in L, \forall r \in r\left(\mu_{l, r}^{-}, \mu_{l, r}^{+}\right) \\
& 0 \leq g r_{r}, \forall r \in r\left(\pi_{r}\right)
\end{aligned}
$$

Renewable generators are confronted with a similar profit maximization as conventional generators, subtracting their operational and investment costs from their market revenues. However, an additional revenue stream is received from a subsidy scheme for renewables which takes the form of an hourly capacity-based premium. Variable costs are defined as $\mathrm{VCR}_{\mathrm{r}}$ and annualized investment costs $\mathrm{CCR}_{\mathrm{r}}$. Through constraint (5), production is constrained by the installed generation capacity and its availability factor $g r_{r} \bullet \mathrm{AVA}_{\mathrm{l}, \mathrm{r}}$ in each period. The renewable generator spills its production whenever it cannot be absorbed by demand. Spillage is not an active decision variable in our model, but can be calculated at equilibrium in each period as:

$$
\text { spillage }=\sum_{r \in R}\left(g r_{r} \cdot \mathrm{AVA}_{\mathrm{l}, \mathrm{r}}\right)-x r_{l, r}
$$

\section{Electricity Consumers}

Electricity consumers are inelastic and have no decision variables in their objective to minimize costs (7). They are price takers in the electricity market and carry the total subsidy costs associated with the renewable premium prem to support RES generators.

Minimize

$$
\sum_{l \in L}\left(\left(\lambda_{l}^{E L} \bullet \mathrm{D}_{\mathrm{l}} \bullet \mathrm{T}_{\mathrm{l}}\right)+\left(\text { prem } \bullet g r_{r} \cdot \mathrm{T}_{\mathrm{l}}\right)\right)
$$

\section{Electricity Market Clearing Constraint}

The electricity market clearing constraint (8) endogenously determines the market price $\lambda_{l}^{E L}$ for each period with the objective of minimizing total energy costs for the electricity sector. The renewable target constraint (9) requires that a percentage of gross electricity consumption must be met by non-spilled RES electricity production calculated on an annual basis. An exogenous RES target is based on consumption of inelastic consumers while any incremental demand from PTG is automatically served by RES that is spilled. The dual variable of this constraint re-enters the renewable generator optimisation problem to form an hourly capacity based premium. The non-negativity constraint (10) ensures a positive price.

Minimize 
Subject to

$$
\left.\sum_{l \in L}\left(\left(\sum_{r \in R} x r_{l, r}\right)+\left(\sum_{s \in S} x_{l, s}\right)-\mathrm{D}_{1}-d p t g_{l}\right) \cdot \mathrm{T}_{l} \cdot \lambda_{l}^{E L}\right)
$$

$$
\begin{gathered}
\sum_{l \in L} \sum_{r \in R} x r_{r} \cdot T_{l}-\left(\operatorname{RENTARGET} \cdot \sum_{l \in L}\left(\mathrm{D}_{1} \cdot \mathrm{T}_{\mathrm{l}}\right)\right)-\sum_{l \in L}\left(d p t g_{\mathrm{l}} \cdot \mathrm{T}_{\mathrm{l}}\right) \geq 0(\text { prem }) \\
\lambda_{l}^{E L} \geq 0 \forall l \in L\left(\eta_{l}^{E L}\right)
\end{gathered}
$$

\subsubsection{Gas Market}

\section{Shippers and Long Term Contracts}

A shipper may have a portfolio of Long Term Contracts (LTCs) in which price formulas may differ due to execution date, indices, flexibility, among others, therefore a simplified procurement cost function was assumed, which has also been similarly used in del Valle et al. (2017). Given we do not attempt to model strategic behavior of gas shippers, we represent the perfectly competitive outcome of multiple shippers as one shipper with one procurement cost function. This shipper's procurement cost function is represented by an affine function with intercept LTCint and slope LTCslope. The objective of each shipper is to maximize its profit, which is equal to revenues from sales on the gas market minus its total procurement costs.

Maximize

$$
\sum_{l \in L}\left(\left(\text { LTCint }+ \text { LTCslope } \bullet q_{l, c}\right)-\lambda_{l}^{G a s}\right) \cdot q_{l, c}
$$

Subject to

$$
q_{l, c} \geq 0, \quad \forall l \in L, \forall c \in C\left(\mu_{l, c}\right)
$$

For a more detailed discussion of LTCs, Neumann et al. (2015) summarize the literature on long term contracts in the natural gas sector and document a database. LTCs are relevant for new infrastructure decisions as shown by Kotek et al. (2016) in analyzing the impact of the Nord Stream 2 pipeline on gas prices and welfare of market participants under anticipated responses for long term contracts.

\section{Conventional Demand Gas}

Gas consumers have an inelastic demand $D G_{1}$ and have the objective to minimize costs (13) but they do not have any decision variables. Gas consumers are price-takers, but they do not contribute to the subsidy scheme to support renewable electricity generators.

Minimize

$$
\sum_{l \in L} \lambda_{l}^{G a s} \cdot \mathrm{DG}_{1} \cdot \mathrm{T}_{1}
$$

\section{Gas Market Clearing Constraint}

The gas market clearing constraint endogenously determines the market price $\lambda_{l}^{\text {Gas }}$ with the objective of minimizing total energy costs for the gas sector. The non-negativity constraint (15) ensures a positive price.

Minimize

$$
\sum_{l \in L}\left(\left(\sum_{c \in C}\left(q_{l, c}\right)-\mathrm{DG}_{\mathrm{l}}-\sum_{s \in S}\left(x_{l, s}\right)+\left(\operatorname{dptg}_{l} \cdot \mathrm{CONV}\right)\right) \cdot \mathrm{T}_{\mathrm{l}} \cdot \lambda_{l}^{G a s}\right)
$$


Subject to

$$
\lambda_{l}^{\text {Gas }} \geq 0 \forall l \in L\left(\eta_{l}^{\text {Gas }}\right)
$$

\subsubsection{Power-to-gas}

\section{Market Coupling}

PTG arbitrages perfectly between the electricity and gas market while taking into account the exogenous conversion efficiency CONV and price in both markets $\lambda_{l}^{E L}$ and $\lambda_{l}^{G A S}$. As a load in the electricity market and a supply source in the gas market, PTG operations $d p t g_{l}$, is the twosided decision variable linking the markets together. The PTG's market coupling role solves the optimization problem (16)-(17). Constraint (16) limits electricity consumption of PTG $d p t g_{l}$ to the installed capacity PTGCAP. In the primary version of the model, used throughout the paper, the installed capacity of PTG is an exogenous parameter and the model solves repeatedly iterating over a number of PTG capacities, increasing by $50 \mathrm{MW}$ increments in each solve.

\section{Maximize}

$$
\left.\sum_{l \in L}\left(\left(\operatorname{dptg}_{l} \bullet \mathrm{CONV} \bullet \lambda_{l}^{G A S}\right)-\left(d p t g_{l} \bullet \lambda_{l}^{E L}\right)\right) \bullet \mathrm{T}_{l}\right)-(\mathrm{PTGCAP} \bullet \mathrm{PTGINVC})
$$

Subject to

$$
0 \leq \operatorname{dptg}_{l} \leq \mathrm{PTGCAP} \quad \forall l \in L\left(\delta_{l}^{-}, \delta_{l}^{+}\right)
$$

Two additional formulations of the model are advanced version which only modify the optimization problem or constraint of the PTG actor: the endogenized PTG capacity investment version and the PTG injection limit constraint version. These formulations are necessary to compare and contrast results with the primary version of the model.

The endogenized PTG capacity investment version makes PTGCAP a decision variable of the PTG actor. This model reformulation (18)-(19) is only utilized in section 3.2.2.2. Welfare Effects.

\section{Maximize}

$$
\left.\sum_{l \in L}\left(\left(\operatorname{dptg}_{l} \bullet \mathrm{CONV} \bullet \lambda_{l}^{G A S}\right)-\left(\operatorname{dptg}_{l} \bullet \lambda_{l}^{E L}\right)\right) \bullet \mathrm{T}_{l}\right)-(p t g c a p \bullet \mathrm{PTGINVC})
$$

Subject to

$$
0 \leq \operatorname{dptg}_{l} \leq \text { ptgcap } \forall l \in L\left(\delta_{l}^{-}, \delta_{l}^{+}\right)
$$

The PTG injection limit constraint version keeps PTGCAP as an exogenous parameter in the optimization problem, but adds a constraint placing an upper bound on how much $\mathrm{dptg}_{l}$ can be injected by volume per period. Using Table 1, in considering the energy and volume density under equal conditions, the ratio for the relative volume occupied by hydrogen and methane are calculated and put it in terms of MWh. $1 \mathrm{MWh}$ of hydrogen takes approximately three time more volume than $1 \mathrm{MWh}$ of methane. This is incorporated into the hydrogen injection limit constraint (20) and is only utilized in section 3.2.2.4. Effect of an injection limit.

\section{Table 1: Gas density values}




\begin{tabular}{|l|l|l|}
\hline & Gross Heating Value $(\mathrm{MJ} / \mathrm{kg})$ & Density $(\mathrm{kg} / \mathrm{m} 3)$ \\
\hline Hydrogen & 142.2 & 0.09 \\
\hline Methane & 52.2 & 0.777 \\
\hline
\end{tabular}

Subject to

$$
\left(\text { injlim } \bullet \sum_{l \in L} \mathrm{DG}_{\mathrm{l}}\right)-\sum_{l \in L}\left(\operatorname{dptg}_{l} \bullet \mathrm{CONV} \bullet 3\right) \geq 0 \quad \forall l \in L\left(\kappa_{l}\right)
$$

\section{Results}

Detailed in the following section, we advance a stylized numerical example in order to analyse the welfare and price effects of electricity and gas market coupling with PTG.

\subsection{Numerical Example}

\subsubsection{Electricity Market}

The stylized electricity market is composed of two sets of generation technologies: two conventional generators - Open Cycle Gas Turbine and Combined Cycle Gas Turbine (OCGT \& CCGT) - and one renewable generator (i.e. wind). Data assumptions for these generation technologies are based on a study conducted by the Belgian electricity TSO, Elia (2017). Each generation technology has a representative new-built capacity costs and variable costs (excluding fuel, emissions and personnel costs). These Gas Fired Power Plants' (GFPP) variable costs are higher for OCGT than for CCGT which accounts for differences in conversion efficiencies. Both GFPP face the same fuel costs due to purchases on the gas market, which when summed together are the total variable costs in operations. The annualized investment costs were determined based on a 20 year economic lifetime, weighted average cost of capital of $6 \%$ and assumed fixed operation and maintenance costs for each technology. Lastly, annual availability factors were assigned, $30 \%$ of installed capacity for RES and $100 \%$ for conventional. A summary of the data assumptions appears in Table 2 . Variable costs for the conventional gas generators increase in terms of MWh in order to conduct the simulation of a carbon price.

\section{Table 2: Generators data assumptions}

\begin{tabular}{|l|l|l|l|}
\hline Technology & $\begin{array}{l}\text { Variable costs } \\
€ / M W h: \mathrm{VC}_{\mathrm{s}} \& \mathrm{VCR}_{\mathrm{r}}\end{array}$ & $\begin{array}{l}\text { Annualized investment costs } \\
€ l \mathrm{MW} \text {.year: } \mathrm{CC}_{\mathrm{s}} \& \mathrm{CC}_{\mathrm{r}}\end{array}$ & Availability \% \\
\hline CCGT & 2 & 94500 & $100 \%$ \\
\hline OCGT & 11 & 64500 & $100 \%$ \\
\hline $\begin{array}{l}\text { RES - } \\
\text { i.e. wind }\end{array}$ & 0 & 159000 & $30 \%$ \\
\hline
\end{tabular}

The demand of inelastic electricity consumers is represented by a Load Duration Curve (LDC) $\mathrm{D}_{1}=22000 \mathrm{MW}-1.37$ hours which is taken from Joskow (2006). This LDC is subdivided into 10 periods of 876 hours each. Therefore, the instantaneous balance between supply and demand is not incorporated, nor are ramping or other technical generation constraints.

\subsubsection{Gas Market}

The stylized gas market is comprised of two sets of gas supplies: the renewable based hydrogen gas injected by PTG and conventional natural gas accessed via LTCs by shippers. Both are considered perfectly substitutable and measured in $€ / M W h$. Here we assume no 
alternative gas supplies from LNG or other renewable gases to the gas market. We represent the outcome of perfectly competitive shippers as a single LTC procurement cost function. We take the assumed gas price of $18 € / M W h$ as in Lynch et al. (2018) for the LTC intercept and add a LTC slope as in del Valle et al. (2017) for the upward sloping LTC procurement cost function of a shipper. The assumptions are specified in Table 3.

\section{Table 3: Gas shipper's LTC procurement cost assumptions}

\begin{tabular}{|l|l|}
\hline Intercept of Long Term Contract $€$ & Slope of Long Term Contract $€ / G W h$ \\
\hline 18 & .25 \\
\hline
\end{tabular}

The electricity sector's GFPP and inelastic gas consumers are the two sources of demand participating in the gas market. The GFPP are elastic in responding to gas prices and are therefore another linking asset participating in both the electricity and gas market simultaneously. The inelastic gas consumers have equal demand in each period and this demand was derived in such a way that the inelastic electricity and gas demand are of equal size. The inelastic gas demand per period was determined by taking the annual inelastic electricity demand in MWh from the LDC and dividing it by the number of hours. Therefore, this gas demand is uncorrelated with the electricity LDC. Although gas demand typically has a seasonal profile, the use of a constant inelastic demand in all periods attempts to implicitly capture the gas storage flattening demand which we do not explicitly model. Cretì (2009) provides a comprehensive discussion on natural gas storage in the European context, which is relevant to understand the role of gas storage in terms of seasonality and flexibility. We do not explicitly model gas storage in such detail.

\subsubsection{Power-to-gas}

The primary driver of PTG investment costs is the technology costs of electrolyzers. A recent report by Agora Verkehrswende et al. (2018) provide a summary of current and future electrolyzer costs which have been estimated in various studies. We assume a conversion efficiency of $80 \%$ for electrolysis in line with this report forecasted for future low temperature electrolysis. Given the costs of the PTG installation will evolve into the future, PTG investment cost is a parameter that we vary with the following range of: $0,200,500$ and 1000 in $€ / \mathrm{kW}$. These investment costs are annualized based on a 25 year economic life, 6\% WACC and $2 \%$ of capital costs for fixed O\&M, taken from Enea Consulting (2016).

\subsubsection{Renewable energy targets discussion}

Following a revision of the Renewable Energy Directive in the Clean Energy for all Europeans Package in 2018, the EU has set a binding renewable energy target of $32 \%$ of energy from renewable sources in the Union's gross final consumption of energy by 2030 (European Union, 2018). Gross final consumption of energy includes energy needs for industry, transport, heat and electricity. According to the accompanying Regulation on the Governance of the Energy Union and Climate Action, how each Member State (MS) will contribute to the achievement of this goal, alongside additional objectives for energy efficiency improvements and greenhouse gas emissions reductions, will be further detailed in its National Energy and Climate Plans for the 2021-2030 period. Each MS's 2020 renewable energy targets will be the bare minimum that must be met. Many MSs have pursued RES targets via the deployment of renewables in the electricity sector, and we utilize an electricity RES target as given for our stylized setting. We vary the electricity RES target as a main parameter in line with the high shares of renewables in the electricity system for different Member States mentioned in the introduction. Ambitious and binding RES targets send a clear market signal and incentives for RES investment, and is included in our model for this reason. 


\subsection{Results}

First, a baseline in which the long-run market equilibrium when an RES target is set and no PTG is installed is explained. The baseline is the reference point to which the later welfare analysis will be compared. Second, the price effects of PTG on the electricity and gas markets will be discussed. Third, the impacts of PTG on sector and total welfare will be summarized with an accompanying sensitivity analysis. Fourth, limitations of our model and approach are discussed.

\subsubsection{Baseline - case without power-to-gas}

The case of no PTG provides a baseline for later making a comparison of the impact of PTG on electricity and gas markets. In this case, the electricity market has only one source of demand defined by the inelastic Load Duration Curve (LDC) over 10 periods and the optimal mix of generation technologies is selected such that the exogenous RES target set is satisfied. In requiring a specified percentage of energy consumed to be supplied by renewables, the RES target drives a minimum amount of renewable capacity to be installed, as depicted for multiple RES targets in Figure 2. The RES capacity required to satisfy a given RES target must take into account the $30 \%$ annual RES availability factor to obtain firm capacity. Without a RES target, no RES would be installed because it is not the least cost resource participating in the market.

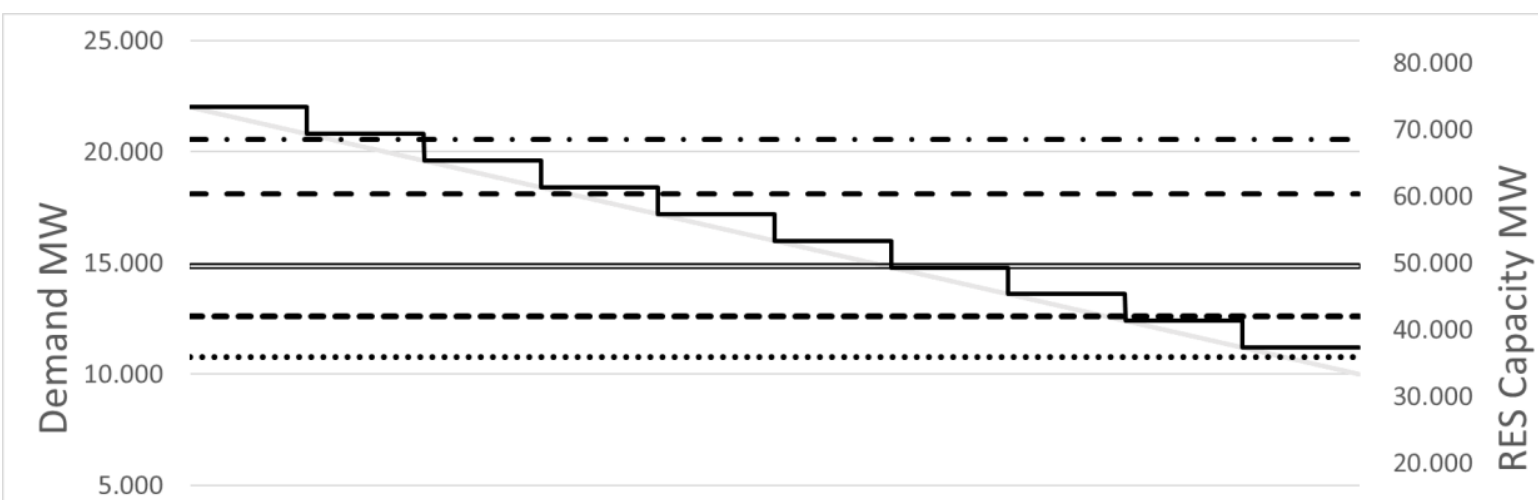

10.000

\section{0

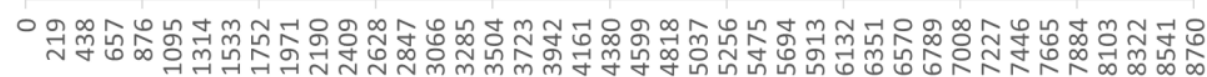

Hours

\section{Figure 2: Impact of RES Targets on RES Capacity Installed}

Spillage only occurs at RES targets greater than $65 \%$ and the amount of spillage is the area underneath the RES target line and above the LDC. For each incremental $5 \%$ RES target above $65 \%$, the marginal quantity of RES capacity installed increases due to spillage. RES capacity investment decisions are strongly dependent on the RES target set. Given an RES target of $95 \%$, the RES capacity required is $60,415 \mathrm{MW}$ and this results in a firm capacity of 18,125 MW. As depicted in Figure 3, for this scenario energy spillage occurs in low demand periods. The remaining generation capacity is met by the least cost GFPP technology, which will produce in peak demand periods. 


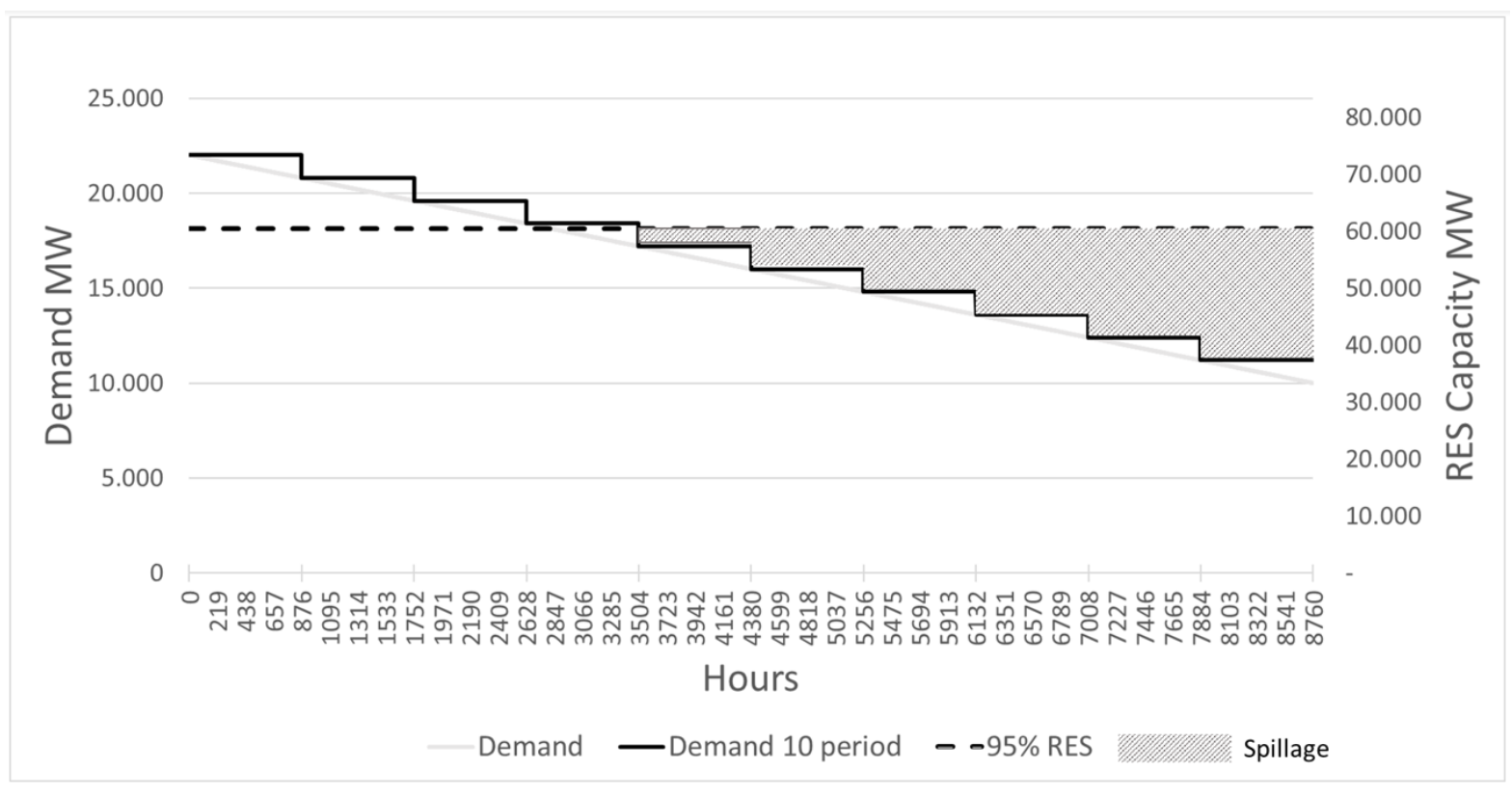

Figure 3: RES Capacity and Spillage in Electricity Market with 95\% RES Target

The electricity market price is cleared for each period and extended to all 876 hours in that period. When spilling of RES occurs in a period, the market clearing price is $0 € / M W h$. Otherwise, it is set either by the conventional generator's variable costs according to the merit order or by scarcity pricing in peak periods for the recovery of fixed investment costs based on the dual variable of the generator's capacity constraint. Given RES is not the least cost technology, the capacity-based RES premium is endogenously determined to make-up for insufficient electricity market revenues such that RES generators recover investment costs and meet their zero profit condition.

Electricity consumers benefit when electricity market prices are $0 € / M W h$ when RES place downward pressure on prices. However, at the same time, the out-of-market capacitybased premium is a subsidy costs borne by electricity consumers to support higher RES targets. As illustrated in Figure 4, higher RES targets increase total costs for electricity consumers in the case with no PTG because of significant subsidies for RES generators.

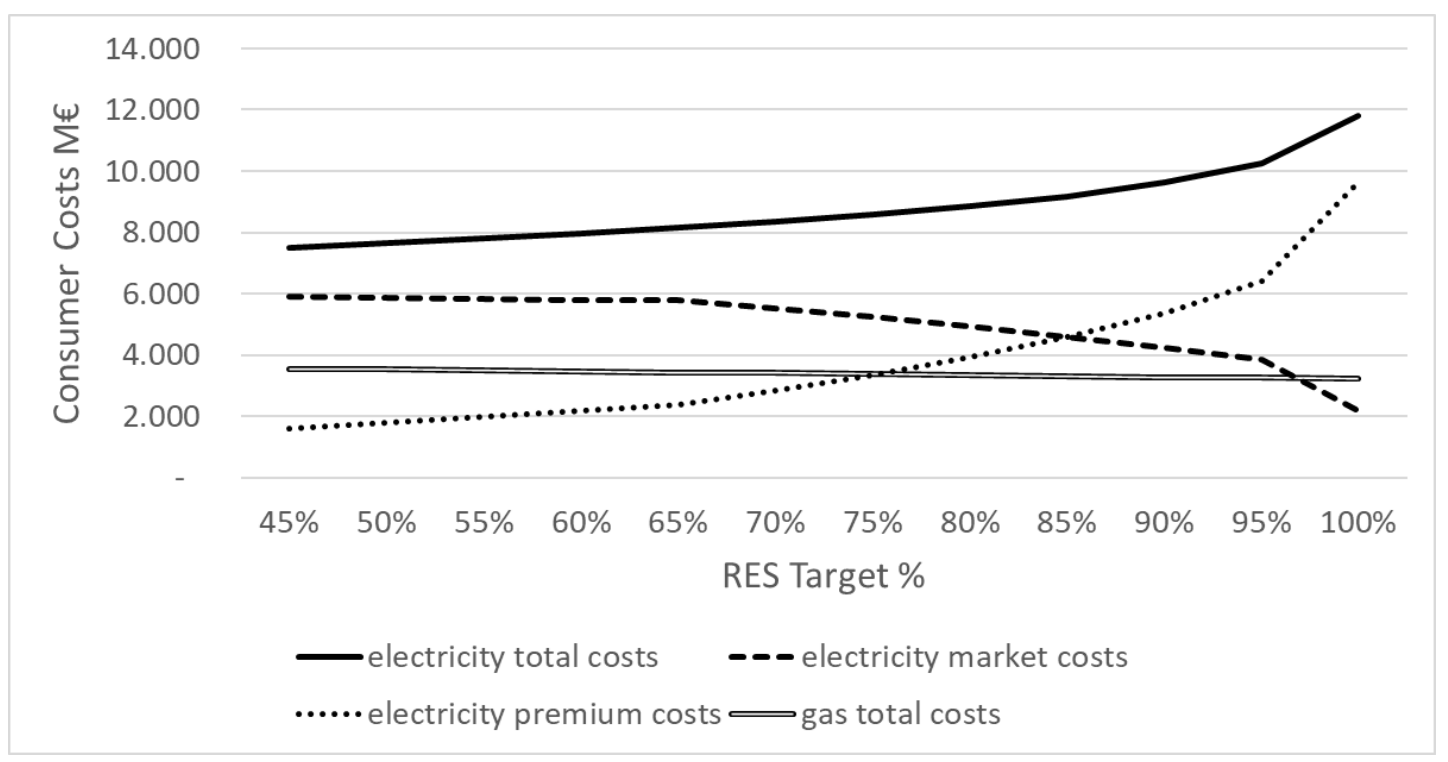

Figure 4: Impact of RES targets on Sector Welfare with no PTG 
In the same instance of no PTG, the gas market has only one source of supply being the shipper's LTC to satisfy both the demand of inelastic gas consumers and GFPPs. The impact of RES targets on the gas market takes place through the participation of GFPP. When GFPP capacity is substituted in favor of RES capacity due to higher RES targets, this directly affects the quantity of gas demanded from the gas market, as depicted in Figure 5 . This reduction in demand lowers procurement cost for the shipper and translates into lower gas prices which end up benefiting inelastic gas consumers.

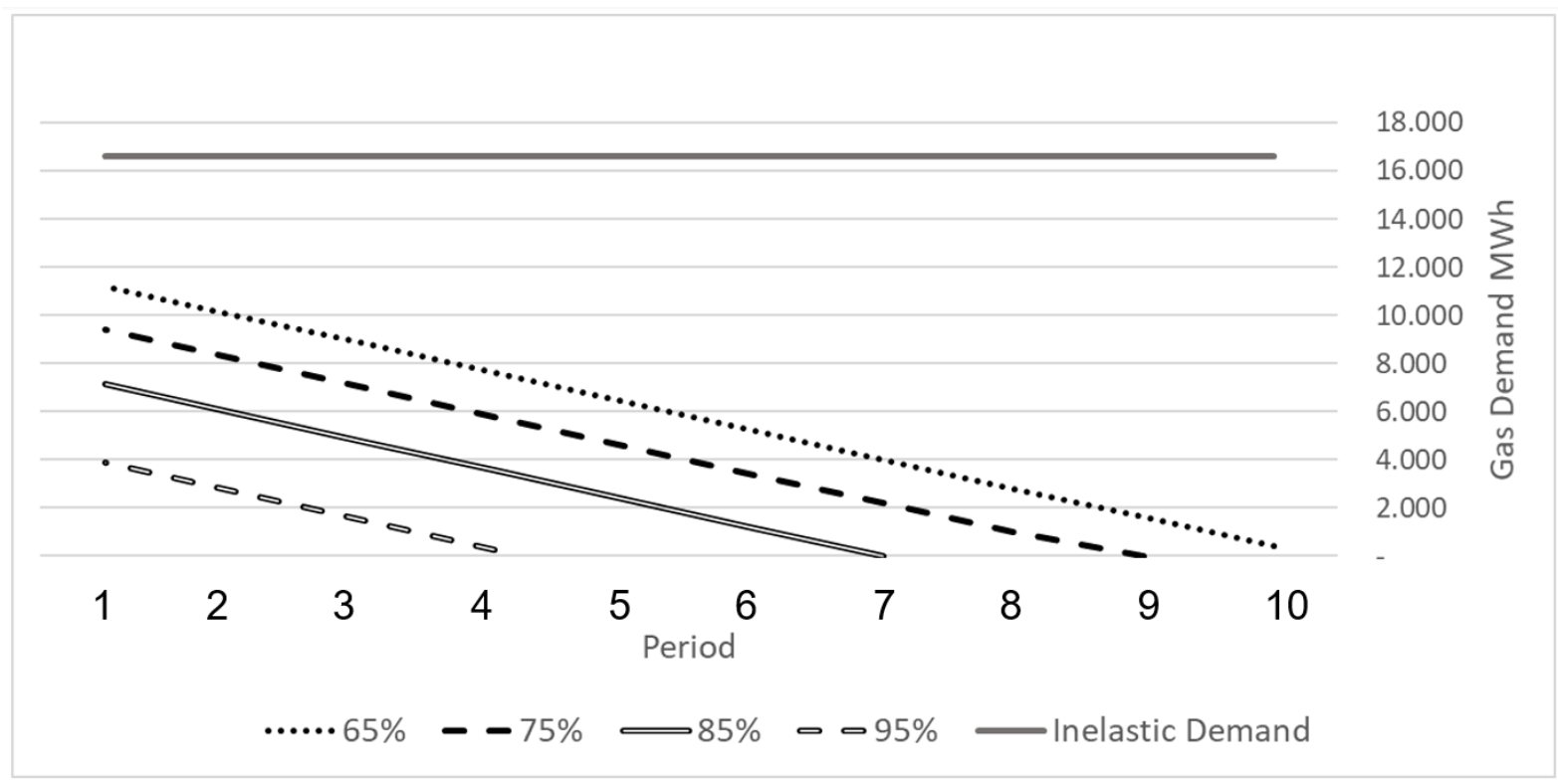

Figure 5: Impact of RES Targets on Gas Market Demand

\subsubsection{Case with power-to-gas}

\subsubsection{Price Effects}

When PTG is introduced into the model, its participation affects price formation in the electricity market through its arbitrage objective as a market coupling agent. Here the price effect induced by PTG participating in the electricity market is described in detail. When renewables are spilled in a given period, the electricity market price is $0 € / \mathrm{MWh}$. In a given period, if you do not have enough PTG capacity installed to evacuate all of this spillage, the price remains $0 € / \mathrm{MWh}$. On the other hand, similar to what has been observed in Lynch et al. (2018), Vandewalle et al. (2015) and Green et al. (2011), once the spillage is absorbed in a given period, the electricity price is set by the perfectly competitive participation of PTG based on its short term zero profit conditions. This condition ignores sunk investment costs, meaning PTG operates as long as the electricity it consumes and subsequently converts into hydrogen can be sold for at least the price in the gas market. This inter-fuel arbitrage can be reached through reorganizing PTG's short term zero profit condition:

$$
\left(\text { ElectPrice }_{l} * \frac{1}{\text { CONV_EFF }_{-}}\right) \geq \text {GasPrice }_{l} \forall l
$$

For example, if the gas market price is $20 € / \mathrm{MWh}$, then at a $80 \%$ conversion efficiency, the competitive price set by PTG in the electricity market is $16 € / M W h$. However, it is possible that there is insufficient PTG capacity to evacuate all of the renewable spillage in all periods. This leads to PTG setting the electricity market clearing price only in some periods and others remain at $0 € / \mathrm{MWh}$. This price-setting behavior at iterated installed capacities of PTG for a 
selected scenario is shown in Table 4 . The electricity prices set by conventional generators in peak periods 1-4 are not impacted by the price-setting of PTG because they do not produce nor receive revenues in these periods.

Table 4: Electricity Market Clearing Prices for PTG Installed Capacities in Scenario 95\% RES Target \& $0 € / \mathrm{kw}$ PTG Investment Costs

\begin{tabular}{|c|l|l|l|l|l|l|l|l|l|}
\hline & \multicolumn{7}{|c|}{ Electricity Market Clearing Prices } & \\
& \multicolumn{7}{|c|}{ per period for iterated installed capacities of PTG } & \\
\hline Period & \multicolumn{1}{|c|}{0} & 950 & 2150 & 3350 & 4450 & 5750 & 6950 & MW \\
\hline 1 & 107.75 & 107.75 & 107.75 & 107.75 & 107.75 & 107.75 & 107.75 & \\
\hline 2 & 33.82 & 33.82 & 33.82 & 33.82 & 33.82 & 33.82 & 33.82 & \\
\hline 3 & 33.52 & 33.52 & 33.52 & 33.52 & 33.52 & 33.52 & 33.52 & \\
\hline 4 & 31.47 & 31.47 & 31.47 & 31.47 & 31.47 & 31.47 & 31.47 & \multirow{2}{*}{ E/MWh } \\
\hline 5 & 0 & 17.57 & 17.57 & 17.57 & 17.57 & 17.57 & 17.57 & \\
\hline 6 & 0 & 0 & 17.38 & 17.38 & 17.38 & 17.38 & 17.38 & \\
\hline 7 & 0 & 0 & 0 & 17.19 & 17.19 & 17.19 & 17.19 & \\
\hline 8 & 0 & 0 & 0 & 0 & 17.00 & 17.00 & 17.00 & \\
\hline 9 & 0 & 0 & 0 & 0 & 0 & 16.80 & 16.80 & \\
\hline 10 & 0 & 0 & 0 & 0 & 0 & 0 & 16.61 & \\
\hline
\end{tabular}

Figure 6 illustrates the same scenario in which a RES target of $95 \%$ leads to spillage in multiple periods and therefore an incentive for PTG to be installed to absorb it. As more PTG capacity is installed, the electricity market price is set by the inter-fuel arbitrage and eventually takes effect in all periods. This explains why the maximum PTG revenues occurs at $4500 \mathrm{MW}$ where the arbitrage margins of PTG's gas sales in periods with $0 € / M W h$ electricity prices are substantial, but as more capacity is added there is an erosion of its revenues from arbitrage. Therefore, adding greater installed capacities of PTG reduces the revenues until it reaches its long-run perfectly competitive outcome. The downward spikes in PTG profits reflect this price-setting effect of PTG in a period and appears large due to the market clearing price in a period extending over 876 hours at a time. Zero profits are reached at $6950 \mathrm{MW}$ although marginal deviations from the precise optimal can also be explained by lumpiness in increments of PTG capacity and the number of hours in each time period used.

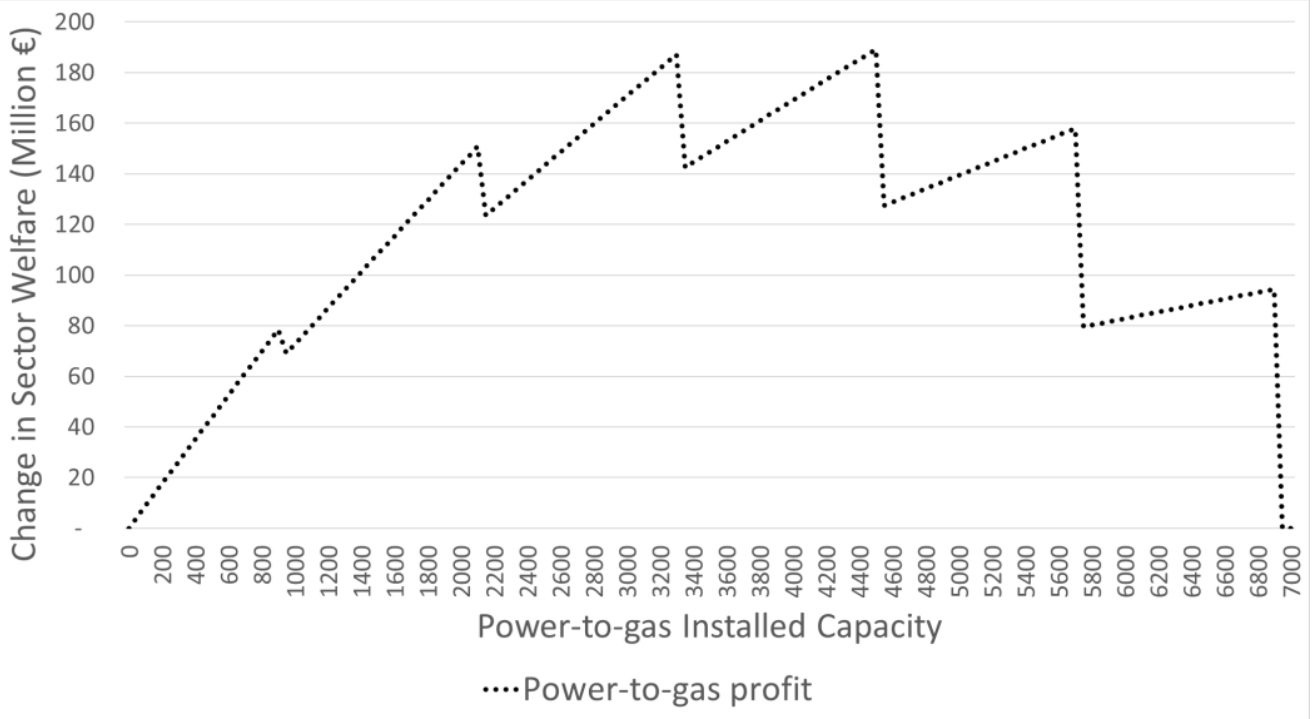

Figure 6: Within a Scenario Analysis 95\% RES Target \& $0 € / k w$ PTG Investment Costs 
When higher PTG investment costs are considered, arbitrage profits must be significant enough to recover its investment costs. As a result, the PTG plant may not be profitable, except when PTG installed capacity is limited such that it does not absorb all spillage and the arbitrage revenues in these zero price periods make investment recovery possible. In the next subsection, this price-setting behavior will be analysed with respect to the impact on sector and total welfare.

\subsubsection{Welfare Effects}

Each combination of RES target and PTG annualized investment cost form a single scenario to analyse the impact of PTG on electricity and gas markets. For each scenario, in iterating from the baseline of $0 \mathrm{MW}$ of PTG capacity by increments of $50 \mathrm{MW}$, we obtain a frontier of perfectly competitive outcomes which are sector equilibrium points representing optimizing agents. A scenario of $95 \%$ RES and $200 € / \mathrm{kW}$ PTG investment costs illustrated in Figure 7 demonstrates the welfare analysis process applied to all scenarios. The baseline welfare for each sector is a nominal welfare amount measured in millions of $€$ to which change in welfare is compared for equilibrium points of the iterated PTG capacities. The long-run equilibrium can be identified by when total welfare, which is the sum of electricity welfare, gas welfare and PTG profits, is maximized. This grid search for agent-specific welfare and total system welfare equilibrium points confirm whether a misalignment in incentives is present.

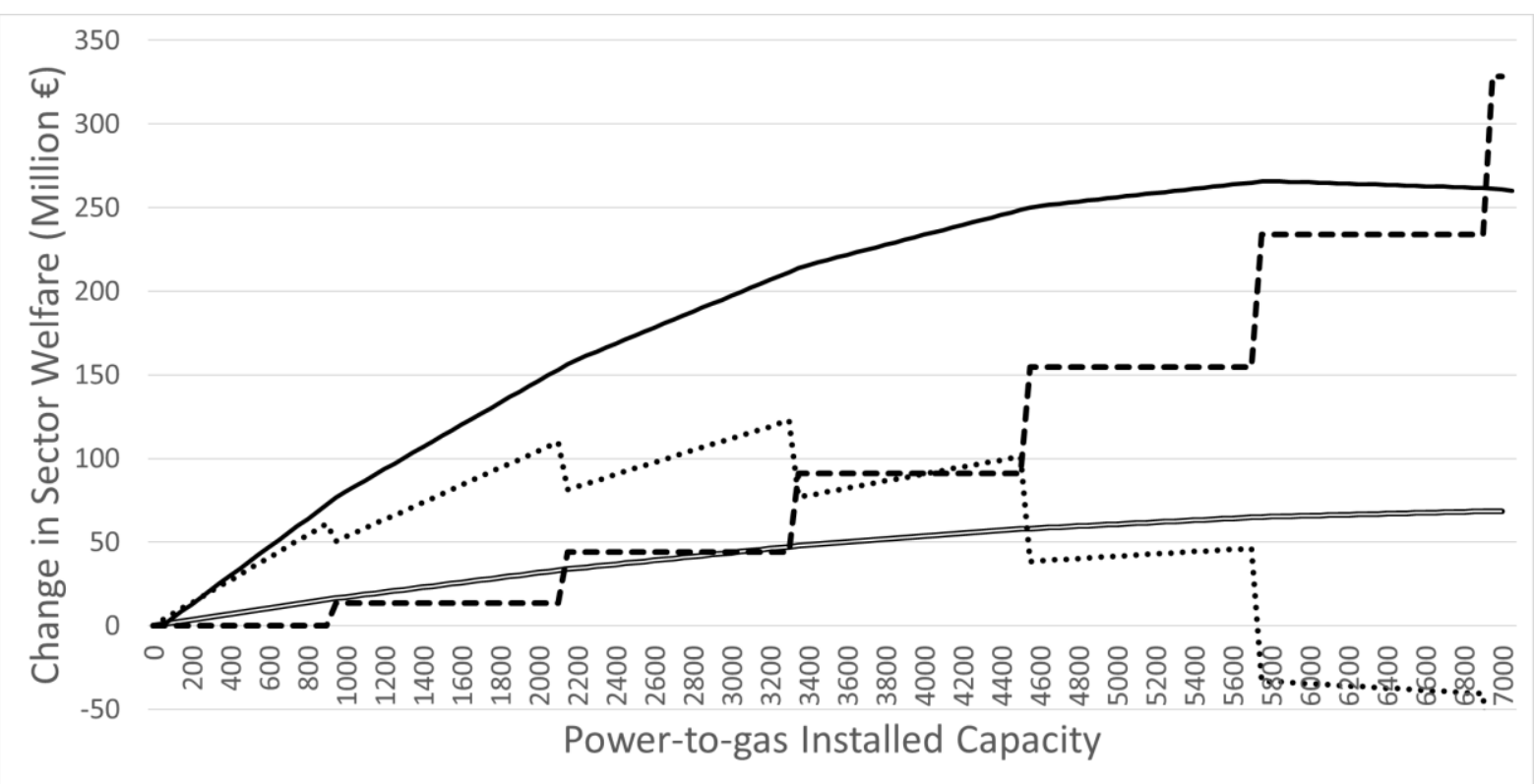

-Total Welfare --Electricity Welfare —Gas Welfare ....Power-to-gas profit

Figure 7: Within a Scenario Analysis 95\% RES Target \& $200 € /$ ww PTG Investment Costs

In this example, we do not observe a misalignment between sectors. In this scenario, the optimal equilibrium point for total system welfare is maximized at $5750 \mathrm{MW}$ of PTG. Both the electricity and gas consumers benefit from PTG at the total welfare optimal equilibrium. For scenarios which have a positive change in total welfare and therefore an installed capacity of PTG greater than 0 , both the electricity and gas sector benefit. The rationale underlining welfare changes across equilibrium points as more PTG is added will be explained further. The positive welfare improvement in the gas sector can be explained by how PTG participates as a new supply source in the gas market. The gas market price formation is strongly dependent on the LTC procurement cost function. When the domestic supply source of hydrogen replaces some LTC imports, there is a slight downward pressure on gas prices, as 
observed in Vandewalle et al. (2015). This slight decrease in the gas price positively benefits gas consumers, although marginally. Given this is a long-run equilibrium model, producer surplus of gas shippers is 0 .

The positive welfare improvement in the electricity sector can be explained by how PTG productively uses otherwise spilled renewables and reduces the costs of the renewable premium for electricity consumers. The renewable energy premium is endogenously determined by the model to offset any market revenue shortfall of renewable generators such that RES investment costs are recovered. PTG, when deployed, can absorb spillage and thereby improves the capacity factors of the renewable generator's fleet and plays a pricesetting role in the electricity market. As previously discussed, PTG absorption of zero marginal cost renewables can have direct price effects on the electricity market, leading to a price greater than $0 € / M W h$. This price increase negatively affects electricity consumers. However, this loss is compensated by the reduction in the premium due to higher capacity factors of renewables which receive a non-zero price for their production. Overall, the net impact of the price making behavior of PTG on electricity welfare is positive, signifying that the gains from the reduction in renewable premium costs are greater than the loss from higher prices in the power market. Given this is a long-run equilibrium model, producer surplus of all generators is 0 .

Note however we do observe a small issue with misaligned incentives related to the PTG actor. At the optimal welfare point, the PTG actor is making a loss. In the above scenario, depicted in Figure 7, this loss is partially explained by lumpiness. Note that this lumpiness can decrease after introducing smaller increments in PTG capacity and/or introducing more demand periods ${ }^{1}$. However, we noticed from some scenarios the issue is more than only lumpiness. In a couple scenarios, as in Figure 8, PTG is always loss-making, but is welfare optimal to invest in it at $1250 \mathrm{MW}$. The intuition behind this observation is that subsidizing PTG can make sense to reduce the cost of RES subsidies.

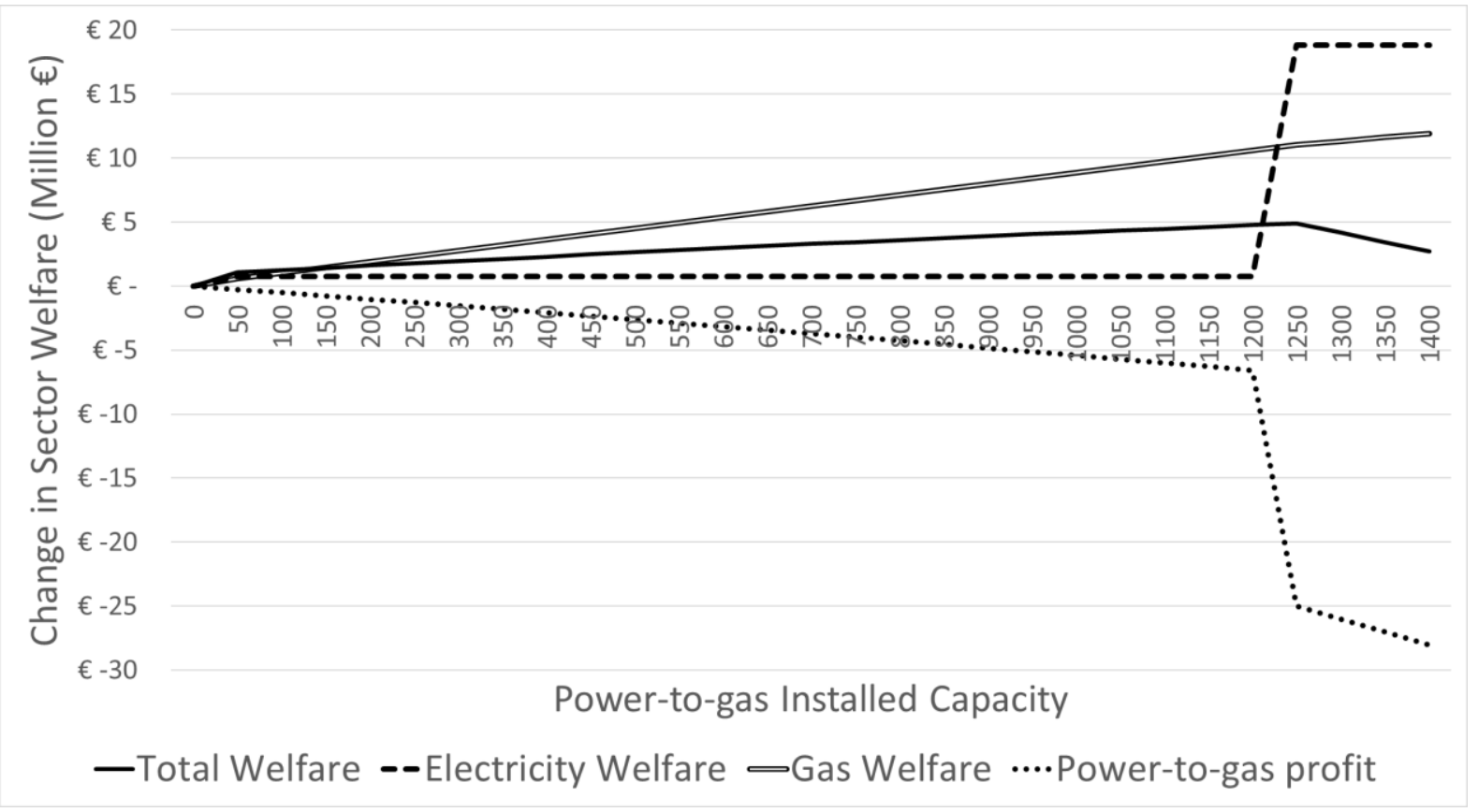

Figure 8: Potential for Misaligned Incentives in Welfare Analysis Scenario

\footnotetext{
${ }^{1}$ We checked for this issue of lumpiness relative to these two parameters.
} 
Table 5 provides a summary of the optimal installed capacity of PTG for multiple scenarios covering different combinations of RES targets and PTG investment costs. The positive total welfare improvement is calculated relative to the baseline of $0 \mathrm{MW}$ of PTG for an exogenous RES target. For all scenarios, the optimal PTG installed capacity appears in the first row, and the positive change in total welfare $(\mathrm{M} €)$, if observed, is listed in the second row. In the third row, PTG profit $(\mathrm{M} €)$ is listed to further compare the welfare distribution. PTG installed capacity is $0 \mathrm{MW}$ when there is a negative change $(-\Delta)$ in total welfare, which means that if PTG is not installed because it is not welfare enhancing.

Table 5: Welfare Analysis - Base Case

\begin{tabular}{|c|c|c|c|c|}
\hline \multicolumn{5}{|c|}{ SCENARIOS } \\
\hline \multicolumn{4}{|c|}{ power-to-gas costs $€ / k w$} & \multirow[b]{2}{*}{ RES Target } \\
\hline 1000 & 500 & 200 & 0 & \\
\hline \multicolumn{4}{|c|}{ no spilling } & $55 \%$ \\
\hline \multicolumn{4}{|c|}{ no spilling } & $60 \%$ \\
\hline \multicolumn{4}{|c|}{ no spilling } & $65 \%$ \\
\hline $0 \mathrm{MW}$ & $0 \mathrm{MW}$ & $0 \mathrm{MW}$ & $500 \mathrm{MW}$ & \multirow{3}{*}{$70 \%$} \\
\hline$-\Delta$ & $-\Delta$ & $-\Delta$ & $8 \mathrm{M} €$ & \\
\hline- & - & - & $0 \mathrm{M} €$ & \\
\hline $0 \mathrm{MW}$ & $0 \mathrm{MW}$ & $250 \mathrm{MW}$ & $1450 \mathrm{MW}$ & \multirow{3}{*}{$75 \%$} \\
\hline$-\Delta$ & $-\Delta$ & $3 \mathrm{M} €$ & $28 \mathrm{M} €$ & \\
\hline- & - & $-1 M €$ & $0 \mathrm{M} €$ & \\
\hline $0 \mathrm{MW}$ & $50 \mathrm{MW}$ & $1300 \mathrm{MW}$ & $2500 \mathrm{MW}$ & \multirow{3}{*}{$80 \%$} \\
\hline$-\Delta$ & $1 \mathrm{M} €$ & $19 \mathrm{M} €$ & $65 \mathrm{M} €$ & \\
\hline- & $0 \mathrm{M} €$ & $-6 \mathrm{M} €$ & $0 \mathrm{M} €$ & \\
\hline $0 \mathrm{MW}$ & $1250 \mathrm{MW}$ & $2450 \mathrm{MW}$ & $3650 \mathrm{MW}$ & \multirow{3}{*}{$85 \%$} \\
\hline$-\Delta$ & $4 \mathrm{M} €$ & $58 \mathrm{M} €$ & $126 \mathrm{M} €$ & \\
\hline- & $-25 M €$ & $-12 \mathrm{M} €$ & $0 \mathrm{M} €$ & \\
\hline $0 \mathrm{MW}$ & $2650 \mathrm{MW}$ & 3900 MW & $5100 \mathrm{MW}$ & \multirow{3}{*}{$90 \%$} \\
\hline$-\Delta$ & $37 \mathrm{M} €$ & $132 \mathrm{M} €$ & $228 \mathrm{M} €$ & \\
\hline- & $-16 \mathrm{M} €$ & $-21 \mathrm{M} €$ & $0 \mathrm{M} €$ & \\
\hline $900 \mathrm{MW}$ & $4450 \mathrm{MW}$ & $5750 \mathrm{MW}$ & $6950 \mathrm{MW}$ & \multirow{3}{*}{$95 \%$} \\
\hline $6 \mathrm{M} €$ & $117 \mathrm{M} €$ & $265 \mathrm{M} €$ & $396 \mathrm{M} €$ & \\
\hline$-9 \mathrm{M} €$ & $-30 \mathrm{M} €$ & $-33 \mathrm{M} €$ & $0 \mathrm{M} €$ & \\
\hline $4450 \mathrm{MW}$ & $7200 \mathrm{MW}$ & 9600 MW & $10800 \mathrm{MW}$ & \multirow{3}{*}{$100 \%$} \\
\hline $140 \mathrm{M} €$ & $429 \mathrm{M} €$ & $684 \mathrm{M} €$ & $890 \mathrm{M} €$ & \\
\hline$-61 \mathrm{M} €$ & $-57 \mathrm{M} €$ & $-60 \mathrm{M} €$ & $0 \mathrm{M} €$ & \\
\hline
\end{tabular}


From our stylized model, we observe that both the RES target and PTG investment costs are important factors in making the business case. A $0 € / \mathrm{kw}$ represents a particular case in which PTG is free or entirely subsidized with the burden not falling on electricity nor gas consumers. The optimal PTG capacity in this case would be enough to absorb $100 \%$ of the spillage for any given RES target. At high RES targets, more spillage occurs across more periods which improves the capacity factor of PTG if installed. At high PTG costs, the welfare benefits for the electricity and gas sector do not often outweigh the PTG investment costs.

In the two scenarios, 95\% RES target \& $1000 € / \mathrm{kw} \mathrm{PTG} \mathrm{costs} \mathrm{and} \mathrm{85 \%} \mathrm{RES} \mathrm{target} \mathrm{\&}$ $500 € / \mathrm{kw}$ PTG costs, also depicted in Figure 8, PTG is always loss-making activity but welfare enhancing. The PTG investment decision was endogenized, as described in section 2.2.3. Power-to-gas, to analyze the solutions dealing with these misaligned incentives. A welfare analysis table is replicated for the endogenized formulation and the results are summarized in Table 6. The two scenarios which are always loss-making yield $0 \mathrm{MW}$ of PTG installed in the endogenous formulation because negative profits cannot be a solution point in long term equilibrium. Furthermore, there are scenarios which have a reduced PTG capacity installed compared to the base case welfare table because of the zero profit condition of the PTG actor in equilibrium. This can be clearly observed in the $90 \%$ or $95 \%$ RES target \& $500 € / \mathrm{kw}$ scenarios, where the optimal PTG capacity is reduced by $1200 \mathrm{MW}$ and $1125 \mathrm{MW}$, respectively. Therefore, the exogenous PTG capacity investment model captures welfare enhancing outcomes which are not solutions in the endogenous PTC capacity investment model due to misaligned incentives.

Table 6: Welfare Analysis - Endogenized PTG Investment Decision

\begin{tabular}{|c|c|c|c|c|}
\hline \multicolumn{5}{|c|}{ SCENARIOS } \\
\hline \multicolumn{4}{|c|}{ power-to-gas costs $€ / k w$} & \multirow[b]{2}{*}{ RES Target } \\
\hline 1000 & 500 & 200 & $\mathbf{0}$ & \\
\hline \multicolumn{4}{|c|}{ no spilling } & $65 \%$ \\
\hline $0 \mathrm{MW}$ & $0 \mathrm{MW}$ & $0 \mathrm{MW}$ & $467 \mathrm{MW}$ & \multirow{3}{*}{$70 \%$} \\
\hline$-\Delta$ & $-\Delta$ & $-\Delta$ & $8 \mathrm{M} €$ & \\
\hline- & - & - & $0 \mathrm{M} €$ & \\
\hline $0 \mathrm{MW}$ & $0 \mathrm{MW}$ & $212 \mathrm{MW}$ & $1412 \mathrm{MW}$ & \multirow{3}{*}{$75 \%$} \\
\hline$-\Delta$ & $-\Delta$ & $3 \mathrm{M} €$ & $28 \mathrm{M} €$ & \\
\hline- & - & $0 \mathrm{M} €$ & $0 \mathrm{M} €$ & \\
\hline $0 \mathrm{MW}$ & $0 \mathrm{MW}$ & $1257 \mathrm{MW}$ & $2457 \mathrm{MW}$ & \multirow{3}{*}{$80 \%$} \\
\hline$-\Delta$ & $-\Delta$ & $19 \mathrm{M} €$ & $65 \mathrm{M} €$ & \\
\hline- & $0 \mathrm{M} €$ & $0 \mathrm{M} €$ & $0 \mathrm{M} €$ & \\
\hline $0 \mathrm{MW}$ & $0 \mathrm{MW}$ & $2450 \mathrm{MW}$ & $3650 \mathrm{MW}$ & \multirow{3}{*}{$85 \%$} \\
\hline$-\Delta$ & $1 \mathrm{M} €$ & $58 \mathrm{M} €$ & $126 \mathrm{M} €$ & \\
\hline- & $0 \mathrm{M} €$ & $0 \mathrm{M} €$ & $0 \mathrm{M} €$ & \\
\hline $0 \mathrm{MW}$ & $1450 \mathrm{MW}$ & 3880 MW & $5080 \mathrm{MW}$ & \multirow{3}{*}{$90 \%$} \\
\hline$-\Delta$ & $34 \mathrm{M} €$ & $132 \mathrm{M} €$ & $228 \mathrm{M} €$ & \\
\hline- & $0 \mathrm{M} €$ & $0 \mathrm{M} €$ & $0 \mathrm{M} €$ & \\
\hline $0 \mathrm{MW}$ & 3325 MW & $5725 \mathrm{MW}$ & $6925 \mathrm{MW}$ & \multirow{3}{*}{$95 \%$} \\
\hline$-\Delta$ & $116 \mathrm{M} €$ & $265 \mathrm{M} €$ & $396 \mathrm{M} €$ & \\
\hline- & $0 \mathrm{M} €$ & $0 \mathrm{M} €$ & $0 \mathrm{M} €$ & \\
\hline $3600 \mathrm{MW}$ & $7200 \mathrm{MW}$ & $9600 \mathrm{MW}$ & $10800 \mathrm{MW}$ & \multirow{3}{*}{$100 \%$} \\
\hline $135 \mathrm{M} €$ & $429 \mathrm{M} €$ & $684 \mathrm{M} €$ & $890 \mathrm{M} €$ & \\
\hline $0 \mathrm{M} €$ & $0 \mathrm{M} €$ & $0 \mathrm{M} €$ & $0 \mathrm{M} €$ & \\
\hline
\end{tabular}


The installed capacities of PTG found in the welfare analysis Table 5 and Table 6 describe a particular sector coupling configuration and is subject to change based on power system characteristics. These factors will be considered later in the context specific sensitivity analysis.

\subsubsection{Effect of cost-competitiveness of renewable generators}

Another impact of PTG on the electricity market is the renewable premium amount needed by RES generators in order to be competitive against conventional generators. When PTG is setting the electricity market price above $0 € / M W h$, then more market revenues support renewable investment recovery, thereby replacing part of the out-of-market capacity based premium. For the 95\% RES target and $200 € / \mathrm{kw}$ PTG investment cost scenario depicted in Figure 9, at the welfare optimal installed capacity of $5750 \mathrm{MW}$, the share of the premium of total revenue recovered was reduced by $13 \%$ of total RES costs in favor of market-based revenues. Here we see that moderate amounts of PTG capacity can significantly contribute to the reduction of spilled renewables. Spillage is reduced by $95 \%$ to $1,029 \mathrm{TWh}$ from 20,629 TWh after installing 5,750 MW of PTG in the above scenario. Moderate amounts of PTG can significantly reduce RES spillage.

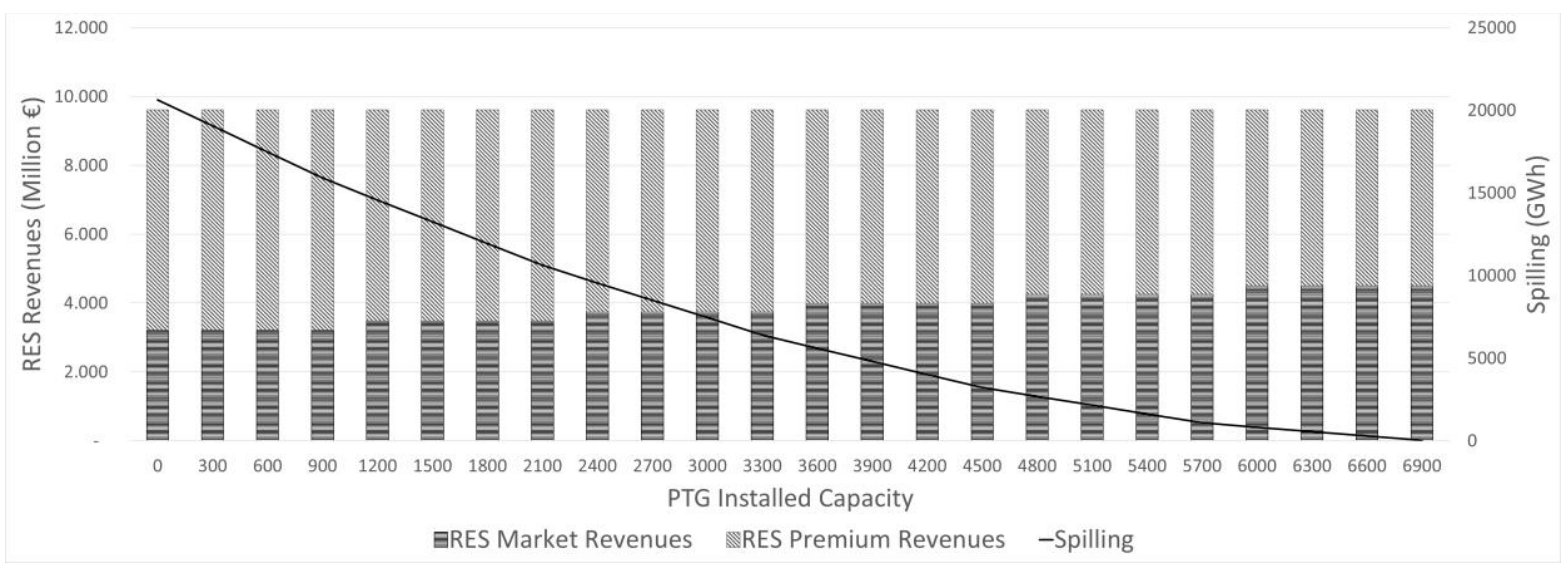

Figure 9: Breakdown of RES Generators' Revenue from Electricity Market and Outof-market Capacity Based Premium

However, the renewable premium is designed to complement revenues recovered from the market and for this reason is sensitive to the electricity price. If the electricity price is sufficiently high, for instance due to high commodity prices (i.e., gas prices or $\mathrm{CO} 2$ prices due to EU ETS), then it is possible RES generators can recover more revenue through the market and reduce the reliance on the premium. We look at cost-competitiveness from two perspectives, namely RES capacity investment costs and a carbon price on conventional gas generators.

In comparing present day RES capacity costs with a future scenario in which RES capacity costs decrease by $25 \%$, the total revenue to be recovered by RES generators decreases, but a premium is still required, meaning renewables are still not cost-competitive. This leads to thinking that the value of spilled energy decreases and the benefits that PTG can deliver to electricity consumers decreases. However, when comparing the base case with the $25 \%$ decrease in RES capacity costs case, we observe the same welfare gains and optimal PTG capacity installed. This observation can be explained by the fact that the welfare gains delivered by PTG to electricity consumers are based on the arbitrage price differences 
between the electricity and gas market. In other words, the opportunity cost of the spillage determines the welfare gains, and not the relative value of the spillage as a function of RES capacity costs.

In simulating a carbon price of $50 € /$ ton applied to conventional gas generators as an additional variable costs in participating in the electricity market and a $50 \%$ reduction in RES investment costs, RES generators can compete in some RES target scenarios $(0 \%-85 \%)$ without the support of a capacity-based premium. The optimal capacity of RES installed is the same in all these scenarios because cost-competitiveness is the driving force. Following the participation of PTG, in absorbing spillage and setting the electricity prices, the profitability of RES generators improves, thereby making them even more competitive relative to conventional generators. This creates an opportunity for RES generators to invest in additional capacity which can displace conventional gas generators' production in mid-peak periods where RES, thanks to PTG, is now even more competitive. The additional RES capacity creates additional spillage in low demand periods, providing further arbitrage opportunities for PTG, leading to downward pressure on gas prices benefiting gas consumers. After installing optimal capacities of PTG, electricity and gas consumers benefit from lower market prices. Jointly, RES generators and PTG are synergistically deployed until cost-parity with conventional generators is reached.

Granted, the carbon price is only placed on the conventional gas generators in this model formulation because we do not model a separate hydrogen market under which the production of hydrogen via conventional steam methane reforming would be subject to the EU ETS. However, given the current allocation scheme of emissions allowances, handed out freely in order to address the competitiveness of specific industries under the threat of carbon leakage, this approach is warranted.

\subsubsection{Effect of an injection limit}

The current gas network cannot accommodate unlimited quantities of hydrogen due to gas quality issues. The choice in blending the hydrogen produced by PTG into the existing methane gas network can ultimately restrict observing the welfare effects in full which were advanced in section 3.2.2.2. Welfare Effects. After introducing a $20 \%$ injection limit by volume per period as described in section 2.2.3. Power-to-gas, the PTG capacity installed, the total welfare and the profitability of PTG are all impacted. As illustrated in Table 7, the injection limit reduces the incentive to install PTG beyond a threshold capacity of $1400 \mathrm{MW}$; the optimal PTG capacity installed appears in the first row. Even though zero electricity prices allows for further arbitrage from the PTG actor and total welfare gains, any additional MW installed cannot participate in any arbitrage opportunity due to the technical injection limit. Where the injection limits are binding at this PTG threshold capacity, PTG profits are positive. The PTG actor cannot install enough capacity to absorb all spillage, so it's arbitrage revenues are significant in the periods with zero electricity prices. Therefore, we observe a redistribution in welfare gains in favor of the PTG actor whose profits appear in the third row. Achieving the full potential of the total welfare gains from Table 5: Welfare Analysis - Base Case are hindered by the injection limit, but PTG profits are no longer negative nor zero in equilibrium for many of the scenarios. In looking at how PTG profits evolve at you increase the RES target, under the $0 € / \mathrm{kw}$ and $200 € / \mathrm{kw}$ ptg costs scenarios respectively, it can be deduced that the capacity factor of the PTG asset increases without increasing the total PTG capacity installed. 
Table 7 : Impact of Injection Limits on Welfare Effects

\begin{tabular}{|c|c|c|c|c|}
\hline \multicolumn{5}{|c|}{ SCENARIOS } \\
\hline \multicolumn{4}{|c|}{ power-to-gas costs $€ / \mathrm{kw}$} & \multirow[b]{2}{*}{ RES Target } \\
\hline 1000 & 500 & 200 & 0 & \\
\hline $0 \mathrm{MW}$ & $0 \mathrm{MW}$ & $0 \mathrm{MW}$ & $500 \mathrm{MW}$ & \multirow{3}{*}{$70 \%$} \\
\hline$-\Delta$ & $-\Delta$ & $-\Delta$ & $8 \mathrm{M} €$ & \\
\hline- & - & - & $0 \mathrm{M} €$ & \\
\hline $0 \mathrm{MW}$ & $0 \mathrm{MW}$ & $250 \mathrm{MW}$ & $1400 \mathrm{MW}$ & \multirow{3}{*}{$75 \%$} \\
\hline$-\Delta$ & $-\Delta$ & $3 \mathrm{M} €$ & $28 \mathrm{M} €$ & \\
\hline- & - & $-1 \mathrm{M} €$ & $20 \mathrm{M} €$ & \\
\hline $0 \mathrm{MW}$ & $50 \mathrm{MW}$ & $1300 \mathrm{MW}$ & $1400 \mathrm{MW}$ & \multirow{3}{*}{$80 \%$} \\
\hline$-\Delta$ & $76 \mathrm{M} €$ & $19 \mathrm{M} €$ & $47 \mathrm{M} €$ & \\
\hline- & $0 \mathrm{M} €$ & $-7 \mathrm{M} €$ & $20 \mathrm{M} €$ & \\
\hline $0 \mathrm{MW}$ & $1250 \mathrm{MW}$ & $1400 \mathrm{MW}$ & $1400 \mathrm{MW}$ & \multirow{3}{*}{$85 \%$} \\
\hline$-\Delta$ & $5 \mathrm{M} €$ & $43 \mathrm{M} €$ & $71 \mathrm{M} €$ & \\
\hline- & $-25 M €$ & $13 \mathrm{M} €$ & $40 \mathrm{M} €$ & \\
\hline $0 \mathrm{MW}$ & $1350 \mathrm{MW}$ & $1400 \mathrm{MW}$ & $1400 \mathrm{MW}$ & \multirow{3}{*}{$90 \%$} \\
\hline$-\Delta$ & $34 \mathrm{M} €$ & $73 \mathrm{M} €$ & $101 \mathrm{M} €$ & \\
\hline- & $12 \mathrm{M} €$ & $53 \mathrm{M} €$ & $80 \mathrm{M} €$ & \\
\hline $900 \mathrm{MW}$ & $1400 \mathrm{MW}$ & $1400 \mathrm{MW}$ & $1400 \mathrm{MW}$ & \multirow{3}{*}{$95 \%$} \\
\hline $6 \mathrm{M} €$ & $68 \mathrm{M} €$ & $109 \mathrm{M} €$ & $136 \mathrm{M} €$ & \\
\hline$-10 \mathrm{M} €$ & $31 \mathrm{M} €$ & $73 \mathrm{M} €$ & $100 \mathrm{M} €$ & \\
\hline $1350 \mathrm{MW}$ & $1400 \mathrm{MW}$ & $1400 \mathrm{MW}$ & $1400 \mathrm{MW}$ & \multirow{3}{*}{$100 \%$} \\
\hline $76 \mathrm{M} €$ & $144 \mathrm{M} €$ & $185 \mathrm{M} €$ & $213 \mathrm{M} €$ & \\
\hline $24 \mathrm{M} €$ & $91 \mathrm{M} €$ & $133 \mathrm{M} €$ & $160 \mathrm{M} €$ & \\
\hline
\end{tabular}

With the blending of hydrogen as the only pathway to market for PTG's hydrogen production and in the absence of any hydrogen storage options or gas storage facilities, the full magnitude of the injection limit still warrants further investigation, but these additions are outside the scope of this paper.

\subsubsection{Context-specific Sensitivity Analysis}

A sensitivity analysis is carried out in order to characterize the impact of power system characteristics on the welfare optimal deployment of PTG. The two most prominent parameters under consideration are the RES availability factor specified in each period and the slope of the Load Duration Curve (LDC). In the base case, the RES availability factor is a constant $30 \%$ in all periods. For an RES installed capacity of $75000 \mathrm{MW}$, the firm capacity provided is then $22500 \mathrm{MW}$ for each hour in all periods. In the base case, the LDC is upward sloping at a rate of $1200 \mathrm{MW}$ per period. The difference between the peak (22000 MW) to baseload (11200 MW) leads to a demand spread of $10800 \mathrm{MW}$. These sensitivities highlight how the potential of PTG can significantly vary from the base case resulting from system-wide parameters which impact energy spillage.

The first set of sensitivities provide alternative RES availabilities (AVA) which are represented graphically in Figure 10. As the electricity LDC is not ordered time series, when 
the RES availability is not constant across all periods, a different specified correlation between electricity demand and RES availability is assumed. Instead of estimating a precise correlation in this regard for a specific geographical location or RES resource, two availability cases positive and negative correlation with LDC - were considered. Each of these cases has an equal average availability as the base case.

For any given renewable capacity installed, a negatively correlated availability (AVA negative) defines RES production to be lower in high demand periods than low demand periods. As RES targets increase, more RES capacity is required to meet high demand periods and additionally more spillage occurs in low demand periods, when compared to the base case. On the other hand, a positively correlated availability (AVA positive) defines RES production to be higher in high demand periods than low demand periods. In this case, spillage is generally reduced in all periods to meet an RES target, when compared to the base case. These differences in installed PTG capacity are summarized in scenario tables in the Appendix. For the same scenario of $95 \%$ RES target and $500 € / \mathrm{kw}$ for PTG costs, the PTG installed capacity is nearly four times greater in the negatively correlated availability case compared to the positively correlated one.

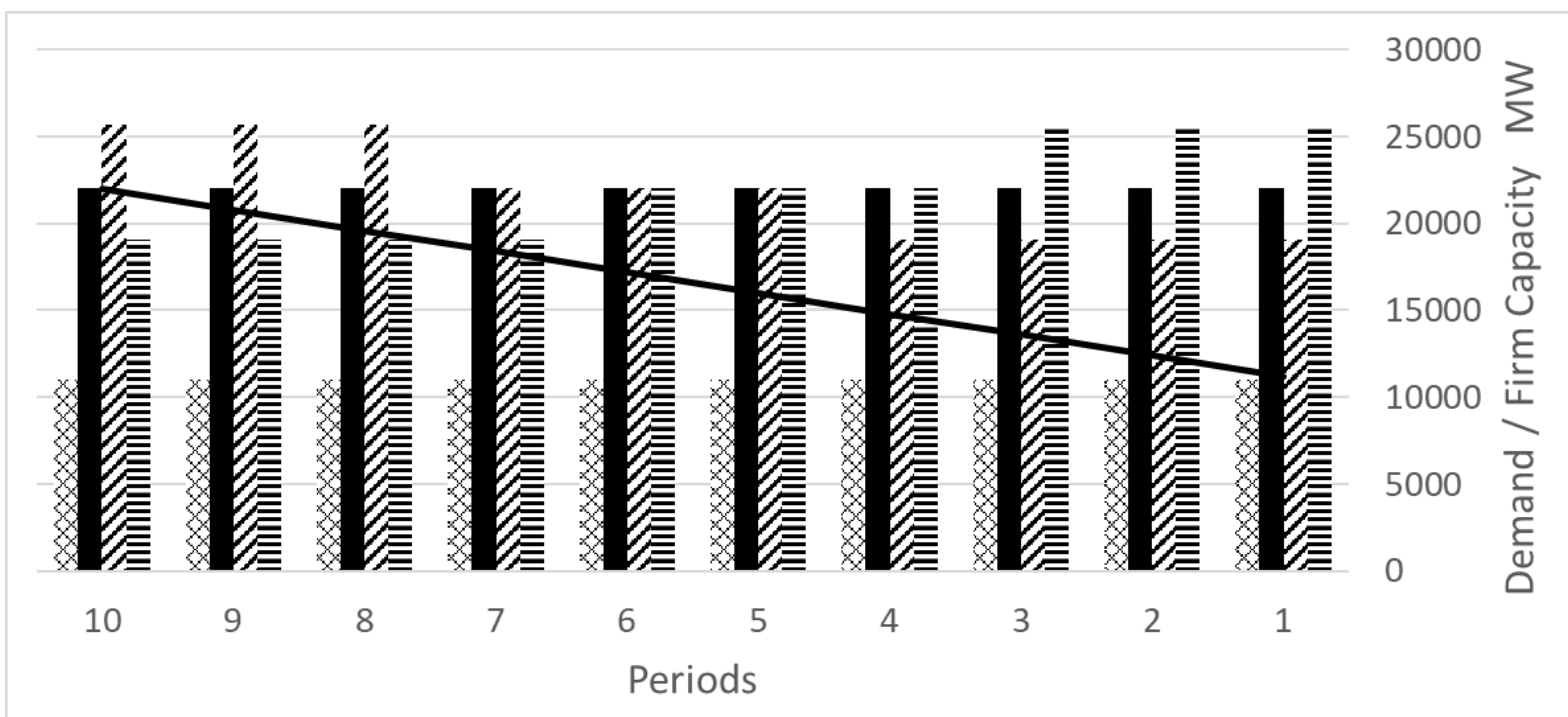

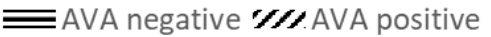

Base Case - AVA constant $X_{\times}$AVA half —Base Case - EL Demand

Figure 10: RES Availability Sensitivities

Another relevant sensitivity simulates the effect of halving the $30 \%$ RES availability factor (AVA half), specifying a 15\% RES availability factor instead. This modification doubles the RES installed capacity required to provide an equal amount of firm capacity, thereby doubling the RES capacity investment necessary.

The second set of sensitivities provide alternative shapes of Load Duration Curves (LDC) which could represent underlying power system characteristics such as seasonality related to demand types observed in a typical year which cause the demand spread between peak load and base load to vary. For example, electric instead of gas used for residential heating applications which typically follow a seasonal temperature dependent pattern could cause a larger demand spread. A flat and steep LDC which are of equal size in gross electricity consumption and have the same 30\% RES availability factor as the base case are considered. For a more steep LDC, spilling begins at lower RES targets (30\%) and there is more spillage overall compared to the base and flat LDC cases. These differences in installed 
PTG capacity are summarized in scenario tables in the Appendix. The most evident observation is when spilling actually begins whether at $35 \%$ in the flat LDC case or $85 \%$ in the steep LDC case. Although these are stylized LDCs represented, reshaping the LDC is a crucial input for determining optimal PTG installed capacity.

The cases examined in the sensitivity analysis each hold a different baseline - market and premium costs for electricity consumers when no PTG is installed - considering all possible RES targets, as explained in Section 3.2.1. These cases can be cross-compared through the change in costs for increasing RES targets incrementally by $5 \%$, as depicted in Figure 11. This cost analysis for electricity consumers directly captures the impact of system parameters on the electricity welfare baseline. When the costs begin to climb over an RES target range, PTG has an opportunity to contribute to welfare improvement, as shown by the cost reductions after installing PTG under the base case at $200 € / \mathrm{kw}$.

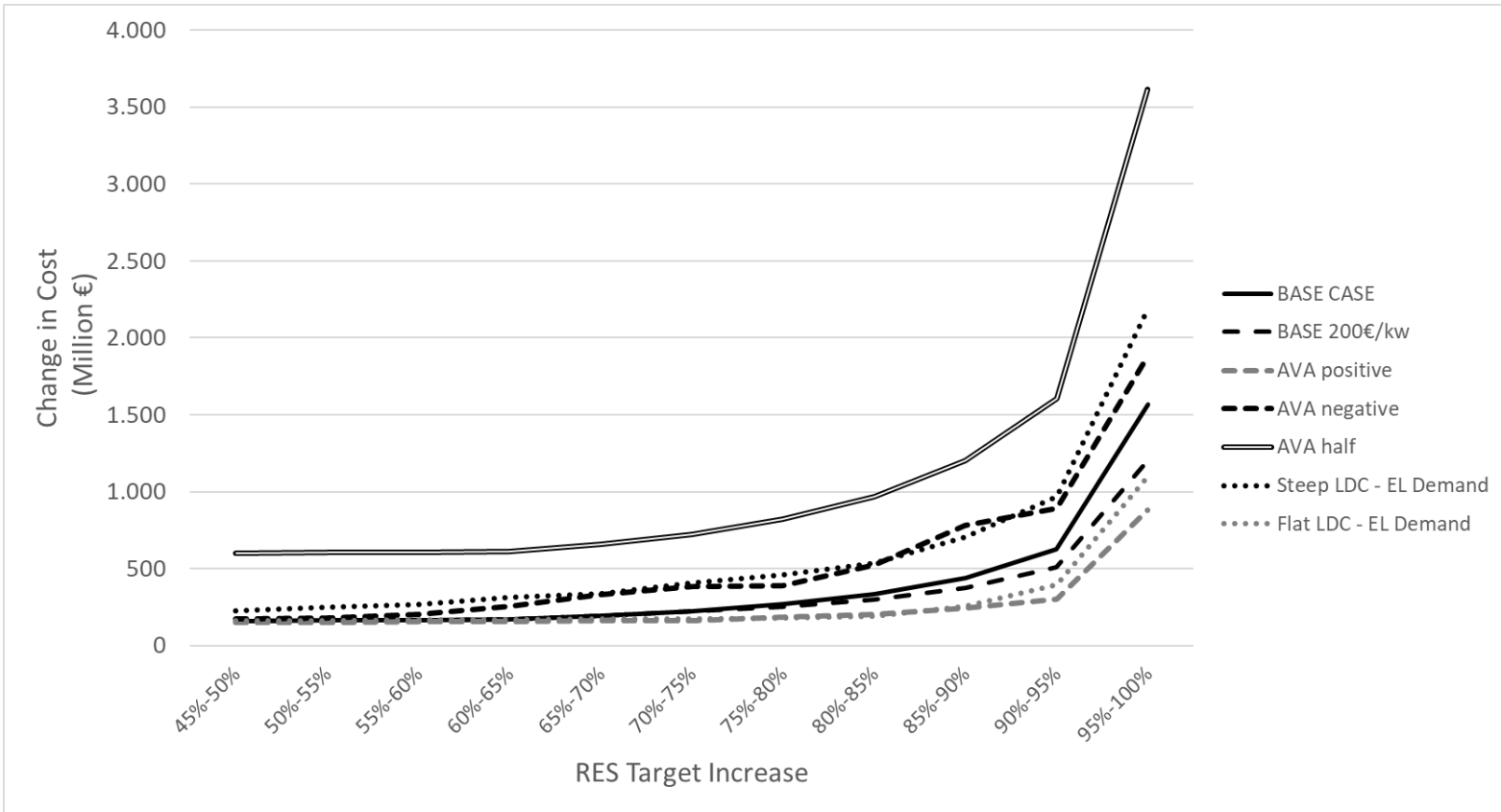

Figure 11: Comparison of Electricity Consumer Cost for Incremental RES Targets Across Sensitivities

\subsubsection{Limitations of our approach and implications for conclusions}

In what follows, we first discuss why our sensitivity analysis is incomplete, and then discuss the implications for the kind of conclusions we can draw from our analysis.

First, why is our sensitivity analysis incomplete? We did illustrate that the conditions under which PTG becomes profitable and significantly improves the welfare of the electricity and gas system, depends on the renewable energy push that is put on that system and the detailed characteristics of that system. There are many factors that play a role, and we did not model all of them. Some omissions imply that we are underestimating the impact of PTG, while others imply that we overestimating the impact of PTG. An illustration of underestimation is that we assume a constant $30 \%$ RES availability factor while actual firm capacity provided by RES could be lower in certain periods. Also we do not model the ancillary services markets, which might be an additional source of revenue for PTG, and an additional system benefit that this technology could deliver. Profitability of PTG could also be impacted by the industrial demand for hydrogen, either through renewable electricity 'green hydrogen' or through precombustion Carbon Capture and Storage 'blue hydrogen', which is also additional revenue that is not considered in the current version of our model. An illustration of overestimation is 
that we focused on PTG as the only means to absorb RES spillage. In practice, however, the competitive landscape offers a diverse set of participating technologies and pathways to market to deal with the 'RES Peak' issue. We do not claim by any means that PTG is the only sector coupling technology to be studied. Further research may eventually show our findings to hold for other power conversion technologies, such as Power-to-heat, Power-to-liquids and batteries.

Second, what are the limitations of our approach and what implications does this have for the kind of conclusions we can draw from the analysis? This model has not been designed to forecast under which assumptions PTG will become profitable and impact the electricity and gas system. As stated in the introduction, we did develop the model to check if we should be concerned about misaligned incentives between the relevant actors in the system. If PTG would become profitable and welfare improving, will the electricity and gas actors spontaneously come together and invest in this technology, or should regulators anticipate that the investment risks to be sub-optimal so that intervention might be needed. In other words, who will benefit from PTG and will we automatically converge to total welfare maximization or is the distribution of welfare such that we might not reach the optimal point. This is what our model has been designed for, and what we focus on in our conclusions. Of course, the model also gives insights on when PTG might become profitable, but these insights need to be treated more carefully so we decided not to highlight them in our conclusions.

\section{Conclusions}

In this paper, we analyzed the welfare and price effects of sector coupling with PTG. We advanced a stylized equilibrium model in order to identify potential misaligned incentives between the relevant actors in the electricity and gas system. In a numerical example, we studied the long-run coupled market equilibrium in multiple scenarios combining electricity RES targets and PTG investment costs. Across scenarios, we studied the price effect induced by the participation of PTG in the electricity market and the impact on the gas market. Within each scenario, we compared the sector and total welfare optimal installed capacity of PTG and distribution of welfare to identify misaligned incentives.

Our three main findings are the following.

First, in order for PTG to recover its investment costs, arbitrage profits must be significant enough. As more PTG capacity is installed, we observe a peak and then erosion of arbitrage revenues. This is due to PTG's price setting role based on the inter-fuel arbitrage in the electricity market when sufficient capacity is installed which can absorb energy spillage.

Second, when PTG is installed in a scenario, signifying a positive impact on system welfare, PTG absorbs spillage which benefits electricity consumers thanks to a reduction in the RES capacity-based premium. At the same time, gas consumers benefit from PTG's alternative supply which reduces gas market prices through a decreased dependence on Long Term Contracts. Therefore, misaligned incentives between sectors may be limited.

Third, the consideration of the cost-competitiveness of renewable generators, an injection limit for hydrogen, and key electricity system parameters such as the correlation between the electricity Load Duration Curve (LDC) and availability of RES are important system characteristics to determine the need for and value that PTG can bring to deal with the 'RES Peak' issue.

We derive two main sector coupling conclusions from these findings. 
First, in scenarios in which PTG is profitable and welfare improving, electricity and gas consumers both benefit from lower prices. This suggests that these sectors have an incentive to cooperate around PTG. We had to analyze all the welfare and price effects to come to this important conclusion.

Second, even if it was not the focus of our analysis, we did discover another issue. In some scenarios, total welfare is maximized at the level of PTG investment that is loss-making for the PTG investor. The intuition is that subsidizing PTG can make sense to reduce the cost of RES subsidies. This then opens the debate for PTG investment support via subsidies and/or grid tariffs.

In other words, we did not find an issue with misaligned incentives where we were expecting to find it, but we did find it where we were not looking for it.

\section{Acknowledgments and Funding}

We would like to thank the concurrent session participants of the $42^{\text {nd }}$ International Association for Energy Economics conference held at HEC Montreal. Additionally, we extend thanks to the participants from the $2^{\text {nd }}$ International Conference on the Economics of Natural Gas held at Paris-Dauphine University in Paris. The PhD research of Martin Roach is supported by the research partnership between Vlerick Business School and Fluxys Belgium. We would like to thank Thierry Deschuyteneer and Rudy Van Beurden from Fluxys for their valuable feedback. This paper has benefited from two anonymous reviewers. Lastly, thank you to Tim Schittekatte, Jean-Michel Glachant and Florence School of Regulation team for their help in the revision of the first working paper. 


\section{References}

ACER, CEER, 2019. The Bridge Beyond 2025 Conclusion Paper.

Agora Verkehrswende, Agora Energiewende, Frontier Economics, 2018. The Future Cost of Electricity-Based Synthetic Fuels.

Belderbos, A., Virag, A., D'haeseleer, W., Delarue, E., 2017. Considerations on the need for electricity storage requirements: Power versus energy. Energy Conversion and Management 143, 137-149. https://doi.org/10.1016/j.enconman.2017.03.074

Blanco, H., Faaij, A., 2018. A review at the role of storage in energy systems with a focus on Power to Gas and long-term storage. Renewable and Sustainable Energy Reviews 81, 1049-1086. https://doi.org/10.1016/j.rser.2017.07.062

Cretì, A., 2009. The Economics of Natural Gas Storage: A European Perspective. Springer Science \& Business Media.

del Valle, A., Dueñas, P., Wogrin, S., Reneses, J., 2017. A fundamental analysis on the implementation and development of virtual natural gas hubs. Energy Economics 67, 520-532. https://doi.org/10.1016/j.eneco.2017.08.001

Elia, 2017. Electricity Scenarios for Belgium towards 2050.

European Union, 2018. DIRECTIVE (EU) 2018/ 2001 OF THE EUROPEAN PARLIAMENT AND OF THE COUNCIL - of 11 December 2018 - on the promotion of the use of energy from renewable sources.

Gabriel, S.A., Conejo, A.J., Fuller, D.J., Hobbs, B.F., Ruiz, C., 2013. Complementarity Modeling in Energy Markets.

Green, R., Hu, H., Vasilakos, N., 2011. Turning the wind into hydrogen: The long-run impact on electricity prices and generating capacity. Energy Policy 39, 3992-3998. https://doi.org/10.1016/j.enpol.2010.11.007

Jones, C.W., Piebalgs, A., Glachant, J.-M., 2018. Energy priorities for the Von der Leyen commission. European University Institute. https://doi.org/10.2870/734901

Joskow, P.L., 2006. Competitive Electricity Markets and Investment in New Generating Capacity. SSRN Electronic Journal. https://doi.org/10.2139/ssrn.902005

Kotek, P., Selei, A., Borbála, T.T., 2016. The Impact of Construction of the Nord Stream 2 Gas Pipeline on Gas Prices and Competition. Regional Center for Energy Policy Research.

Li, Y., Gao, W., Ruan, Y., 2019. Potential and sensitivity analysis of long-term hydrogen production in resolving surplus RES generation-a case study in Japan. Energy 171, 1164-1172. https://doi.org/10.1016/j.energy.2019.01.106

Lynch, M.Á., Devine, M., Bertsch, V., 2018. The role of power-to-gas in the future energy system: how much is needed and who wants to invest? Working Paper.

Neumann, A., Rüster, S., von Hirschhaussen, C., 2015. Long-term contracts in the natural gas industry: Literature survey and data on 426 contracts (1965-2014). DIW Data Documentation, Deutsches Institut für Wirtschaftsforschung.

Saguan, M., Meeus, L., 2014. Impact of the regulatory framework for transmission investments on the cost of renewable energy in the EU. Energy Economics 43, 185194. https://doi.org/10.1016/j.eneco.2014.02.016

Tlili, O., Mansilla, C., Robinius, M., Syranidis, K., Reuss, M., Linssen, J., André, J., Perez, Y., Stolten, D., 2019. Role of electricity interconnections and impact of the geographical scale on the French potential of producing hydrogen via electricity surplus by 2035. Energy 172, 977-990. https://doi.org/10.1016/j.energy.2019.01.138

Vandewalle, J., Bruninx, K., D'haeseleer, W., 2015. Effects of large-scale power to gas conversion on the power, gas and carbon sectors and their interactions. Energy Conversion and Management 94, 28-39. https://doi.org/10.1016/j.enconman.2015.01.038 


\section{Appendix A. KKT Conditions}

$$
\begin{aligned}
& \left(\mathrm{VC}_{\mathrm{s}}+\lambda_{l}^{G a s}-\lambda_{\mathrm{l}}^{\mathrm{EL}}\right) \cdot \mathrm{T}_{\mathrm{l}}-\rho_{\mathrm{l}, \mathrm{s}}^{-}+\rho_{\mathrm{l}, \mathrm{s}}^{+}=0, \quad \forall \mathrm{l} \in \mathrm{L}, \forall \mathrm{s} \in \mathrm{S} \\
& \mathrm{CC}_{\mathrm{s}}-\left(\sum_{l \in L} \rho_{l, \mathrm{~s}}^{+} \cdot \mathrm{T}_{\mathrm{l}}\right)-\xi_{\mathrm{s}}=0, \forall \mathrm{s} \in \mathrm{S} \\
& \left(\mathrm{VCR}_{\mathrm{r}}-\lambda_{l}^{E L}\right)-\mu_{l, r}^{-}+\mu_{l, r}^{+}=0, \forall \mathrm{l} \in \mathrm{L}, \forall \mathrm{r} \in \mathrm{R} \\
& \mathrm{CCR}_{\mathrm{r}}-\sum_{l \in L}\left(\mu_{l, r}^{+} \bullet \mathrm{AVA}_{\mathrm{l}, \mathrm{r}} \bullet \mathrm{T}_{\mathrm{l}}\right)-\sum_{l \in L}\left(\text { prem } \bullet \mathrm{T}_{\mathrm{l}}\right)-\pi_{r}=0, \forall \mathrm{r} \in \mathrm{R} \\
& \sum_{r \in R}\left(x r_{r}\right)+\sum_{s \in S}\left(x_{s}\right)-\mathrm{D}_{\mathrm{l}}-\operatorname{dptg}_{l}=0 \forall \mathrm{l} \in \mathrm{L} \\
& \left(\lambda_{l}^{\text {Gas }}-\left(\text { LTCint + LTCslope } \bullet q_{l, c}\right)-\mu_{l, c}=0, \forall \mathrm{l} \in \mathrm{L}, \forall \mathrm{c} \in \mathrm{C}\right. \\
& \sum_{c \in C}\left(q_{l, c}\right)-\mathrm{DG}_{\mathrm{l}}-\sum_{s \in S}\left(x_{l, s}\right)+\left(\operatorname{dptg}_{l} \cdot \mathrm{CONV}\right)=0, \forall \mathrm{l} \in \mathrm{L} \\
& \lambda_{l}^{E L}-\left(\lambda_{l}^{G A S} \bullet \mathrm{CONV}\right)-\delta_{l}^{-}+\delta_{l}^{+}+\iota_{l}=0 \forall l \in L \\
& 0 \leq \rho_{l, s}^{-} \perp x_{s} \geq 0, \quad \forall l \in L, \forall s \in S \\
& 0 \leq \rho_{l, s}^{+} \perp g_{s}-x_{l, s} \geq 0, \forall l \in L, \forall s \in S \\
& 0 \leq \xi_{s} \perp g_{s} \geq 0, \quad \forall s \in S \\
& 0 \leq \mu_{l, r}^{-} \perp x r_{l, r} \geq 0, \quad \forall l \in L, \forall r \in R \\
& 0 \leq \mu_{l, r}^{+} \perp g r_{r} \bullet \mathrm{AVA}_{\mathrm{l}, \mathrm{r}}-x r_{l, r} \geq 0, \quad \forall l \in L, \quad \forall r \in R \\
& 0 \leq \pi_{r} \perp g R_{r} \geq 0, \quad \forall r \in R \\
& 0 \leq \text { prem } \perp \sum_{l \in L} \sum_{r \in R} x r_{r} \bullet T_{l}-\left(\operatorname{RENTARGET} \bullet \sum_{l \in L}\left(\left(\mathrm{D}_{\mathrm{l}}\right) \bullet \mathrm{T}_{\mathrm{l}}\right)\right)-\sum_{l \in L}\left(\operatorname{dptg}_{\mathrm{l}} \bullet \mathrm{T}_{\mathrm{l}}\right) \\
& \geq 0, \quad \forall l \in L \\
& 0 \leq \mu_{l, c} \perp q_{l, c} \geq 0, \quad \forall \mathrm{l} \in \mathrm{L}, \forall \mathrm{c} \in \mathrm{C} \\
& 0 \leq \eta_{l}^{\text {Gas }} \perp \lambda_{l}^{\text {Gas }} \geq 0, \quad \forall l \in L \\
& 0 \leq \delta_{l}^{-} \perp \text { dptg }_{l} \geq 0, \quad \forall l \in L \\
& 0 \leq \delta_{l}^{+} \perp \text { PTGCAP }-d p t g_{l} \geq 0, \quad \forall l \in L
\end{aligned}
$$


Appendix B. Sensitivity Analysis Tables

B1. RES Availability correlation with Load Duration Curve

\begin{tabular}{|c|c|c|c|c|}
\hline \multicolumn{5}{|c|}{$\begin{array}{l}\text { Sensitivity - RES availability negatively correlated } \\
\text { with Load Duration Curve }\end{array}$} \\
\hline \multicolumn{5}{|c|}{ SCENARIOS } \\
\hline \multicolumn{4}{|c|}{ power-to-gas costs $€ / \mathrm{kw}$} & \multirow{2}{*}{$\begin{array}{c}\text { RES } \\
\text { Target }\end{array}$} \\
\hline 1000 & 500 & 200 & 0 & \\
\hline \multicolumn{4}{|c|}{ no spilling } & $55 \%$ \\
\hline $0 \mathrm{MW}$ & $0 \mathrm{MW}$ & $0 \mathrm{MW}$ & $550 \mathrm{MW}$ & \multirow{2}{*}{$60 \%$} \\
\hline$-\Delta$ & $-\Delta$ & $-\Delta$ & $9 \mathrm{M} €$ & \\
\hline $0 \mathrm{MW}$ & $0 \mathrm{MW}$ & $500 \mathrm{MW}$ & $1700 \mathrm{MW}$ & \multirow{2}{*}{$65 \%$} \\
\hline$-\Delta$ & $-\Delta$ & $7 \mathrm{M} €$ & $37 \mathrm{M} €$ & \\
\hline $0 \mathrm{MW}$ & $650 \mathrm{MW}$ & $1850 \mathrm{MW}$ & $3100 \mathrm{MW}$ & \multirow{2}{*}{$70 \%$} \\
\hline$-\Delta$ & $2 \mathrm{M} €$ & $39 \mathrm{M} €$ & $95 \mathrm{M} €$ & \\
\hline $0 \mathrm{MW}$ & $2150 \mathrm{MW}$ & $3350 \mathrm{MW}$ & $4550 \mathrm{MW}$ & \multirow{2}{*}{$75 \%$} \\
\hline$-\Delta$ & $6 \mathrm{M} €$ & $85 \mathrm{M} €$ & $171 \mathrm{M} €$ & \\
\hline $0 \mathrm{MW}$ & $3600 \mathrm{MW}$ & $4850 \mathrm{MW}$ & $6050 \mathrm{MW}$ & \multirow{2}{*}{$80 \%$} \\
\hline$-\Delta$ & $8 \mathrm{M} €$ & $130 \mathrm{M} €$ & $244 \mathrm{M} €$ & \\
\hline $0 \mathrm{MW}$ & $4450 \mathrm{MW}$ & $6700 \mathrm{MW}$ & $7900 \mathrm{MW}$ & \multirow{2}{*}{$85 \%$} \\
\hline$-\Delta$ & $41 \mathrm{M} €$ & $217 \mathrm{M} €$ & $366 \mathrm{M} €$ & \\
\hline $1300 \mathrm{MW}$ & $4450 \mathrm{MW}$ & $9200 \mathrm{MW}$ & $\begin{array}{c}10450 \\
\text { MW }\end{array}$ & \multirow[t]{2}{*}{$90 \%$} \\
\hline $8 \mathrm{M} €$ & $137 \mathrm{M} €$ & $380 \mathrm{M} €$ & $578 \mathrm{M} €$ & \\
\hline $3700 \mathrm{MW}$ & $6150 \mathrm{MW}$ & $\begin{array}{c}12000 \\
\text { MW }\end{array}$ & $\begin{array}{c}13200 \\
\text { MW }\end{array}$ & \multirow{2}{*}{$95 \%$} \\
\hline $16 \mathrm{M} €$ & $255 \mathrm{M} €$ & $567 \mathrm{M} €$ & $819 \mathrm{M} €$ & \\
\hline $4450 \mathrm{MW}$ & $10600 \mathrm{MW}$ & $\begin{array}{c}17200 \\
\text { MW }\end{array}$ & $\begin{array}{c}18450 \\
\text { MW }\end{array}$ & \multirow{2}{*}{$100 \%$} \\
\hline $140 \mathrm{M} €$ & $572 \mathrm{M} €$ & $1009 \mathrm{M} €$ & $1361 \mathrm{M} €$ & \\
\hline
\end{tabular}




\begin{tabular}{|c|c|c|c|c|}
\hline \multicolumn{5}{|c|}{$\begin{array}{l}\text { Sensitivity - RES availability positively correlated with } \\
\text { Load Duration Curve }\end{array}$} \\
\hline \multicolumn{5}{|c|}{ SCENARIOS } \\
\hline \multicolumn{4}{|c|}{ power-to-gas costs $€ / k w$} & \multirow{2}{*}{$\begin{array}{l}\text { RES } \\
\text { Target }\end{array}$} \\
\hline 1000 & 500 & 200 & 0 & \\
\hline \multicolumn{4}{|c|}{ no spilling } & $55 \%$ \\
\hline \multicolumn{4}{|c|}{ no spilling } & $60 \%$ \\
\hline \multicolumn{4}{|c|}{ no spilling } & $65 \%$ \\
\hline \multicolumn{4}{|c|}{ no spilling } & $70 \%$ \\
\hline \multicolumn{4}{|c|}{ no spilling } & $75 \%$ \\
\hline $0 \mathrm{MW}$ & $0 \mathrm{MW}$ & $0 \mathrm{MW}$ & $400 \mathrm{MW}$ & \multirow{2}{*}{$80 \%$} \\
\hline$-\Delta$ & $-\Delta$ & $-\Delta$ & $6 \mathrm{M} €$ & \\
\hline $0 \mathrm{MW}$ & $0 \mathrm{MW}$ & $0 \mathrm{MW}$ & $\begin{array}{l}1200 \\
M W\end{array}$ & \multirow[t]{2}{*}{$85 \%$} \\
\hline$-\Delta$ & $-\Delta$ & $-\Delta$ & $20 \mathrm{M} €$ & \\
\hline $0 \mathrm{MW}$ & $0 \mathrm{MW}$ & $850 \mathrm{MW}$ & $\begin{array}{l}2050 \\
\text { MW }\end{array}$ & \multirow[t]{2}{*}{$90 \%$} \\
\hline$-\Delta$ & $-\Delta$ & $12 \mathrm{M} €$ & $49 \mathrm{M} €$ & \\
\hline $0 \mathrm{MW}$ & $600 \mathrm{MW}$ & $1850 \mathrm{MW}$ & $\begin{array}{l}3050 \\
\text { MW }\end{array}$ & \multirow[t]{2}{*}{$95 \%$} \\
\hline$-\Delta$ & $9 \mathrm{M} €$ & $45 \mathrm{M} €$ & $101 \mathrm{M} €$ & \\
\hline $1650 \mathrm{MW}$ & $2850 \mathrm{MW}$ & $3950 \mathrm{MW}$ & $\begin{array}{l}5150 \\
\text { MW }\end{array}$ & \multirow{2}{*}{$100 \%$} \\
\hline $65 \mathrm{M} €$ & $179 \mathrm{M} €$ & $278 \mathrm{M} €$ & $375 \mathrm{M} €$ & \\
\hline
\end{tabular}


B2. Shape of Load Duration Curve

\begin{tabular}{|c|c|c|c|c|}
\hline \multicolumn{5}{|c|}{ Sensitivity - Steeper Load Duration Curve } \\
\hline \multicolumn{5}{|c|}{ SCENARIOS } \\
\hline \multicolumn{4}{|c|}{ power-to-gas costs $€ / \mathrm{kw}$} & \multirow{2}{*}{$\begin{array}{c}\text { RES } \\
\text { Target }\end{array}$} \\
\hline 1000 & 500 & 200 & 0 & \\
\hline \multicolumn{4}{|c|}{ no spilling } & $30 \%$ \\
\hline $0 \mathrm{MW}$ & $0 \mathrm{MW}$ & $0 \mathrm{MW}$ & $250 \mathrm{MW}$ & \multirow{2}{*}{$35 \%$} \\
\hline$-\Delta$ & $-\Delta$ & $-\Delta$ & $4 \mathrm{M} €$ & \\
\hline $0 \mathrm{MW}$ & $0 \mathrm{MW}$ & $0 \mathrm{MW}$ & $1200 \mathrm{MW}$ & \multirow{2}{*}{$40 \%$} \\
\hline$-\Delta$ & $-\Delta$ & $-\Delta$ & $20 \mathrm{M} €$ & \\
\hline $0 \mathrm{MW}$ & $0 \mathrm{MW}$ & $0 \mathrm{MW}$ & $2100 \mathrm{MW}$ & \multirow{2}{*}{$45 \%$} \\
\hline$-\Delta$ & $-\Delta$ & $-\Delta$ & $35 \mathrm{M} €$ & \\
\hline $0 \mathrm{MW}$ & $0 \mathrm{MW}$ & $650 \mathrm{MW}$ & $3100 \mathrm{MW}$ & \multirow{2}{*}{$50 \%$} \\
\hline$-\Delta$ & $-\Delta$ & $9 \mathrm{M} €$ & $63 \mathrm{M} €$ & \\
\hline $0 \mathrm{MW}$ & $0 \mathrm{MW}$ & $1700 \mathrm{MW}$ & $4150 \mathrm{MW}$ & \multirow{2}{*}{$55 \%$} \\
\hline$-\Delta$ & $-\Delta$ & $24 \mathrm{M} €$ & $98 \mathrm{M} €$ & \\
\hline $0 \mathrm{MW}$ & $300 \mathrm{MW}$ & $2750 \mathrm{MW}$ & $5200 \mathrm{MW}$ & \multirow{2}{*}{$60 \%$} \\
\hline$-\Delta$ & $1 \mathrm{M} €$ & $45 \mathrm{M} €$ & $139 \mathrm{M} €$ & \\
\hline $0 \mathrm{MW}$ & $1450 \mathrm{MW}$ & $3950 \mathrm{MW}$ & $6400 \mathrm{MW}$ & \multirow{2}{*}{$65 \%$} \\
\hline$-\Delta$ & $4 \mathrm{M} €$ & $82 \mathrm{M} €$ & $198 \mathrm{M€}$ & \\
\hline $0 \mathrm{MW}$ & $2700 \mathrm{MW}$ & $5150 \mathrm{MW}$ & $7600 \mathrm{MW}$ & \multirow{2}{*}{$70 \%$} \\
\hline$-\Delta$ & $11 \mathrm{M} €$ & $123 \mathrm{M} €$ & $262 \mathrm{M} €$ & \\
\hline $0 \mathrm{MW}$ & $4050 \mathrm{MW}$ & $6550 \mathrm{MW}$ & $9000 \mathrm{MW}$ & \multirow{2}{*}{$75 \%$} \\
\hline$-\Delta$ & $36 \mathrm{M} €$ & $187 \mathrm{M} €$ & $352 \mathrm{M} €$ & \\
\hline $0 \mathrm{MW}$ & $4450 \mathrm{MW}$ & 8050 MW & $10500 \mathrm{MW}$ & \multirow{2}{*}{$80 \%$} \\
\hline$-\Delta$ & $74 \mathrm{M} €$ & $265 \mathrm{M} €$ & $459 \mathrm{M} €$ & \\
\hline $0 \mathrm{MW}$ & $4800 \mathrm{MW}$ & $9700 \mathrm{MW}$ & $12150 \mathrm{MW}$ & \multirow{2}{*}{$85 \%$} \\
\hline$-\Delta$ & $129 \mathrm{M} €$ & $365 \mathrm{M} €$ & $590 \mathrm{M} €$ & \\
\hline $1950 \mathrm{MW}$ & $6850 \mathrm{MW}$ & $11750 \mathrm{MW}$ & $14200 \mathrm{MW}$ & \multirow{2}{*}{$90 \%$} \\
\hline $11 \mathrm{M} €$ & $228 \mathrm{M} €$ & $516 \mathrm{M} €$ & $780 \mathrm{M} €$ & \\
\hline $4450 \mathrm{MW}$ & $9450 \mathrm{MW}$ & $14350 \mathrm{MW}$ & $16800 \mathrm{MW}$ & \multirow{2}{*}{$95 \%$} \\
\hline $53 \mathrm{M} €$ & $381 \mathrm{M} €$ & $737 \mathrm{M} €$ & $1050 \mathrm{M} €$ & \\
\hline $7350 \mathrm{MW}$ & $14650 \mathrm{MW}$ & 19550 MW & 20750 MW & \multirow{2}{*}{$100 \%$} \\
\hline $255 \mathrm{M} €$ & $789 \mathrm{M} €$ & $1280 \mathrm{M} €$ & $1677 \mathrm{M} €$ & \\
\hline
\end{tabular}




\begin{tabular}{|c|c|c|c|c|}
\hline \multicolumn{5}{|c|}{ Sensitivity - Flatter Load Duration Curve } \\
\hline \multicolumn{5}{|c|}{ SCENARIOS } \\
\hline \multicolumn{4}{|c|}{ power-to-gas costs $€ / \mathrm{kw}$} & \multirow{2}{*}{$\begin{array}{l}\text { RES } \\
\text { Target }\end{array}$} \\
\hline 1000 & 500 & 200 & 0 & \\
\hline \multicolumn{4}{|c|}{ no spilling } & $55 \%$ \\
\hline \multicolumn{4}{|c|}{ no spilling } & $60 \%$ \\
\hline \multicolumn{4}{|c|}{ no spilling } & $65 \%$ \\
\hline \multicolumn{4}{|c|}{ no spilling } & $70 \%$ \\
\hline \multicolumn{4}{|c|}{ no spilling } & $75 \%$ \\
\hline \multicolumn{4}{|c|}{ no spilling } & $80 \%$ \\
\hline $0 \mathrm{MW}$ & $0 \mathrm{MW}$ & $0 \mathrm{MW}$ & $250 \mathrm{MW}$ & \multirow{2}{*}{$85 \%$} \\
\hline$-\Delta$ & $-\Delta$ & $-\Delta$ & $4 \mathrm{M} €$ & \\
\hline $0 \mathrm{MW}$ & $0 \mathrm{MW}$ & $650 \mathrm{MW}$ & $1250 \mathrm{MW}$ & \multirow{2}{*}{$90 \%$} \\
\hline$-\Delta$ & $-\Delta$ & $10 \mathrm{M} €$ & $32 \mathrm{M} €$ & \\
\hline $0 \mathrm{MW}$ & $1300 \mathrm{MW}$ & $1950 \mathrm{MW}$ & $2550 \mathrm{MW}$ & \multirow{2}{*}{$95 \%$} \\
\hline$-\Delta$ & $19 \mathrm{M} €$ & $67 \mathrm{M} €$ & $115 \mathrm{M} €$ & \\
\hline $2400 \mathrm{MW}$ & $4150 \mathrm{MW}$ & $4800 \mathrm{MW}$ & $5400 \mathrm{MW}$ & \multirow{2}{*}{$100 \%$} \\
\hline $75 \mathrm{M} €$ & $224 \mathrm{M} €$ & $355 \mathrm{M} €$ & $459 \mathrm{M} €$ & \\
\hline
\end{tabular}




\section{Appendix C. Notation}

C.1 Sets

\begin{tabular}{|l|l|}
\hline I & Period of load duration curve \\
\hline S & Conventional technologies \\
\hline r & Renewable technologies \\
\hline & Long term contracts \\
\hline
\end{tabular}

C2. Parameters

\begin{tabular}{|c|c|c|c|}
\hline Type & Name & Description & Unit \\
\hline \multirow[t]{3}{*}{ Demand } & $D_{l}$ & Electricity demand in period I & MW \\
\hline & $D G_{l}$ & Gas demand in period I & MWh \\
\hline & $T_{l}$ & Duration of period I. $\sum T_{l}=8760$ & Hours \\
\hline \multirow{7}{*}{$\begin{array}{l}\text { Electricity } \\
\text { Generation \& } \\
\text { Gas Supply }\end{array}$} & $C C_{S}$ & $\begin{array}{l}\text { Annual investment capacity cost for } \\
\text { conventional s }\end{array}$ & $€ / M W$ \\
\hline & $C C R_{r}$ & $\begin{array}{l}\text { Annual investment capacity cost for } \\
\text { renewable r }\end{array}$ & $€ / M W$ \\
\hline & $V C_{S}$ & Variable cost for conventional s & $€ / M W h$ \\
\hline & $V C R_{r}$ & Variable cost for renewable $r$ & $€ / M W h$ \\
\hline & $A V A_{r, l}$ & Availability factor for renewable $r$ in period I & $\%$ \\
\hline & LTCint $_{c}$ & $\begin{array}{l}\text { Intercept of simplified procurement cost } \\
\text { function of long term contract c }\end{array}$ & $€$ \\
\hline & LTCslope $_{c}$ & $\begin{array}{l}\text { Slope of simplified procurement cost } \\
\text { function of long term contract c }\end{array}$ & $€ / M W h$ \\
\hline \multirow[t]{3}{*}{ Power-to-gas } & PTGCAP & Power-to-gas capacity installed & MW \\
\hline & PTGINVC & $\begin{array}{l}\text { Annual investment capacity cost for power- } \\
\text { to-gas }\end{array}$ & $€ / \mathrm{MW}$ \\
\hline & CONV & Conversion efficiency of power-to-gas & $\%$ \\
\hline $\begin{array}{l}\text { Renewable } \\
\text { Policy }\end{array}$ & RENTARGET & $\begin{array}{l}\text { Minimal annual renewable energy } \\
\text { produced and consumed }\end{array}$ & MWh \\
\hline
\end{tabular}

C3. Variables

\begin{tabular}{|c|c|c|c|}
\hline Type & Name & Description & Unit \\
\hline \multirow[t]{6}{*}{$\begin{array}{l}\text { (Primal) } \\
\text { Variables }\end{array}$} & $x_{l, s}$ & $\begin{array}{l}\text { Generation of conventional plant s in time } \\
\text { period I }\end{array}$ & MW \\
\hline & $g_{s}$ & $\begin{array}{lll}\text { Maximal generation } & \text { (capacity) } \\
\text { conventional plant s }\end{array}$ & MW \\
\hline & $x r_{l, r}$ & Generation of renewable plant $r$ in period I & MW \\
\hline & $g r_{r}$ & $\begin{array}{lll}\text { Maximal generation } & \text { (capacity) of } \\
\text { renewable plant } r & & \\
\end{array}$ & MW \\
\hline & $d p t g_{l, p}$ & Demand of power-to-gas $p$ in period I & MW \\
\hline & $q_{l, c}$ & $\begin{array}{l}\text { Quantity of gas procured from contract c in } \\
\text { period I }\end{array}$ & MWh \\
\hline \multirow[t]{4}{*}{$\begin{array}{l}\text { (Dual) } \\
\text { variables }\end{array}$} & $\rho_{l, S}^{+}$ & $\begin{array}{l}\text { Dual variable for maximal production } \\
\text { constraint for conventional plant } s \text { in period } \\
\text { I }\end{array}$ & $€ / M W h$ \\
\hline & $\rho_{l, s}^{-}$ & Dual variable for non-negativity $x_{l, s}$ & \\
\hline & $\xi_{s}$ & Dual variable for non-negativity $g_{s}$ & \\
\hline & $\mu_{l, r}^{+}$ & $\begin{array}{l}\text { Dual variable for maximal production } \\
\text { constraint for conventional plant } r \text { in period } \\
\text { l }\end{array}$ & $€ / \mathrm{MWh}$ \\
\hline
\end{tabular}




\begin{tabular}{|l|c|l|l|}
\hline & $\mu_{l, r}^{-}$ & $\begin{array}{l}\text { Dual variable for non-negativity constraint } \\
x r_{l, r}\end{array}$ & \\
\cline { 2 - 4 } & $\pi_{r}$ & $\begin{array}{l}\text { Dual variable for non-negativity constraint } \\
g_{r}\end{array}$ & \\
\cline { 2 - 4 } & $p r e m$ & Dual variable for RES target constraint & $€ / \mathrm{MW} . \mathrm{h}$ \\
\cline { 2 - 5 } & $\delta_{l}^{+}$ & $\begin{array}{l}\text { Dual variable for maximal consumption } \\
\text { constraint for power-to-gas in period I }\end{array}$ & $€ / \mathrm{MWh}$ \\
\cline { 2 - 5 } & $\delta_{l}^{-}$ & $\begin{array}{l}\text { Dual variable for non-negativity constraint } \\
d p t g_{l}\end{array}$ & \\
\hline $\begin{array}{l}\text { (Output) } \\
\text { variables }\end{array}$ & $\lambda_{l}^{E L}$ & Electricity price for demand period I & $€ / \mathrm{MWh}$ \\
\cline { 2 - 4 } & $\lambda_{l}^{G a s}$ & Gas price for demand period I & $€ / \mathrm{MWh}$ \\
\hline
\end{tabular}

